NBER WORKING PAPER SERIES

\title{
THE EMPLOYMENT IMPACT OF GREEN FISCAL PUSH: EVIDENCE FROM THE AMERICAN RECOVERY ACT
}

\author{
David Popp \\ Francesco Vona \\ Giovanni Marin \\ Ziqiao Chen \\ Working Paper 27321 \\ http://www.nber.org/papers/w27321 \\ NATIONAL BUREAU OF ECONOMIC RESEARCH \\ 1050 Massachusetts Avenue \\ Cambridge, MA 02138 \\ June 2020
}

This project has been supported in part through the Smart Prosperity Institute Research Network and its Greening Growth Partnership, which is supported by a Social Sciences and Humanities Research Council of Canada Partnership Grant (no. 895-2017-1018), as well as by Environment and Climate Change Canada's Economics and Environmental Policy Research Network (EEPRN). This work was also supported by Horizon 2020 Framework Programme, project INNOPATHS [grant number 730403]. We thank seminar participants at the University of Bremen, APPAM, and Greening Growth Partnership \& Economics and Environmental Policy Research Network Annual Symposium for helpful comments. The views expressed herein are those of the authors and do not necessarily reflect the views of the National Bureau of Economic Research.

NBER working papers are circulated for discussion and comment purposes. They have not been peerreviewed or been subject to the review by the NBER Board of Directors that accompanies official NBER publications.

(C) 2020 by David Popp, Francesco Vona, Giovanni Marin, and Ziqiao Chen. All rights reserved. Short sections of text, not to exceed two paragraphs, may be quoted without explicit permission provided that full credit, including $(\mathcal{O}$ notice, is given to the source. 
The Employment Impact of Green Fiscal Push: Evidence from the American Recovery Act David Popp, Francesco Vona, Giovanni Marin, and Ziqiao Chen

NBER Working Paper No. 27321

June 2020

JEL No. E24,E62,H54,H72,Q58

\section{ABSTRACT}

We evaluate the employment effect of the green part of the largest fiscal stimulus in recent history, the American Recovery and Reinvestment Act (ARRA). Each \$1 million of green ARRA created 15 new jobs that emerged especially in the post-ARRA period (2013-2017). We find little evidence of significant short-run employment gains. Green ARRA creates more jobs in commuting zones with a greater prevalence of pre-existing green skills. Nearly half of the jobs created by green ARRA investments were in construction or waste management. Nearly all new jobs created are manual labor positions. Nonetheless, manual labor wages did not increase.

David Popp

Department of Public Administration

and International Affairs

Syracuse University

The Maxwell School

426 Eggers Hall

Syracuse, NY 13244-1020

and NBER

dcpopp@maxwell.syr.edu

Francesco Vona

OFCE SciencesPo

60 Rue Fedor Dostoïevski

06902 - Sophia Antipolis

France

and SKEMA Business School

francesco.vona@sciencespo.fr
Giovanni Marin

Department of Economics, Society, Politics

Università di Urbino Carlo Bo

Via Aurelio Saffi, 42

61029 Urbino

ITALY

and SEEDS

giovanni.marin@uniurb.it

Ziqiao Chen

Center for Policy Research

Syracuse University

426 Eggers Hall

Syracuse, NY 13244-1020

zchen64@syr.edu 


\section{Introduction}

The effect of environmental policy on employment is still hotly debated and polarized, with advocates on both sides ignoring or exaggerating the labor market costs and benefits of environmental regulations. Advocates of stronger environmental policies argue that such policies create high-paying "green jobs", while critics point to the job losses in energy-intensive industries that they are sure will follow. Previous literature finds that net effect of environmental policies on employment is small especially when general equilibrium effects and offsetting mechanisms are accounted for (Morgenstern et al., 2002; Hafstead and Williams, 2018; Metcalf and Stock, 2020). However, other studies find job losses concentrated in polluting industries (Greenstone, 2002, Kahn and Mansur, 2013) and among unskilled workers (Yip, 2018; Marin and Vona, 2019). Adverse impacts on manual labor are of particular concern for policy-makers, given the secular decline in their employability and wages driven by automation and globalization (Autor et al., 2003; Autor et al., 2013).

While the previous literature has evaluated the effect of policies imposing a cost on pollution (either through standards or prices) on labor markets, less attention has been devoted to the potential of green subsidies opening up new employment opportunities in the so-called green economy. Our paper informs the burgeoning policy debate on green fiscal plans, by focusing on the evaluation of a big push for the green economy, namely the green part of the American Recovery and Reinvestment Act (ARRA, henceforth). The full stimulus package included over $\$ 350$ billion of direct government spending, and an additional \$260 billion in tax reductions (Aldy, 2013). We focus on the direct spending targeted at green investments, which constituted approximately $17 \%$ of all direct government spending in ARRA. Examples of such spending include Department of Energy (DOE) block grants to states to support energy efficiency audits 
and retrofits, investments in public transport and clean vehicles, and Environmental Protection Agency (EPA) spending to clean up brownfield sites. Because a large share of green spending was devoted to public investments, green ARRA may have a cumulative effect stretching beyond the stimulus period (Council of Economic Advisers, 2013, 2014). We thus differentiate between the short- and long-term effect of green ARRA. We evaluate the employment gains triggered by the green stimulus, its heterogeneous effect depending on the level of local green capabilities and the way in which the green stimulus has affected different sectors and groups of workers. Our evaluation is timely and important as proposals for green stimuli investments have attracted a great deal of attention, both as part of possible recovery packages after COVID-19 lockdowns and as part of Green New Deal plans proposed by the European Commission, the International Energy Agency, the International Monetary Fund and some Democrats in the US (Helm, 2020).

Our analysis makes three contributions to the discussion of heterogeneous labor market effects. First, using data on green skills from Vona et al. (2018), we show that the effectiveness of green investments varies depending on the pre-existing skill base of a community. Second, we estimate the effects of green ARRA investments on different sectors and sets of occupations to identify those workers receiving the most benefits from green investments. Third, our focus on heterogeneous effects across different types of workers also adds to the literature on structural transformations and inequality in local labor markets (e.g., Autor et al., 2013; Acemoglu and Restrepo, 2020). A key difference between investments in the green economy, especially in building retrofitting and energy infrastructures, and in automation is that the former increase the relative demand of manual workers, while the latter decreases it. This implies that manual workers that are displaced by carbon pricing policies in energy intensive sectors (Marin and Vona, 2019; Yip, 2019) may find new employment opportunities in sectors related to the green economy, such 
as construction and waste management. Our research considers whether green investments can facilitate this transition in local labor markets.

Our analysis also contributes to the broader literature estimating the effects of the 2009 Recovery Act. We add to the empirical literature on fiscal multipliers looking at the effect of a type of spending, i.e. in the green economy, that will become increasingly important in the future (see Chodorow-Reich, 2019 for a survey). In the spirit of recent contributions seeking to isolate the microeconomics mechanisms of the local multiplier (e.g. Moretti, 2010; Garin, 2018; Dupor and McCrory, 2018; Auerbach et al., 2019), we study the time profile of the effect, the role of key mediating factors and some mechanisms through which the green stimulus impact on the local economy.

Previous literature on other aspects of the Recovery Act exploit geographical variation in expenditures and isolate its exogenous component, and thus a causal effect, using pre-existing formulas to allocate federal funds (Wilson, 2012; Chodorow-Reich et al., 2012; Nakamura and Steinsson, 2014; Dupor and Mehkari, 2016; Chodorow-Reich, 2019). However, identifying the causal effect of the green stimulus presents three additional challenges. First, the green stimulus is small relative to the non-green stimulus. Controlling for non-green ARRA expenditures is essential, but potentially introduces another endogenous variable complicating the identification of the green ARRA effect (Angrist and Pischke, 2008). The trade-off is between an error of misspecification from not including non-green ARRA and a bias in estimating the green ARRA effect for including a bad control (non-green ARRA) correlated with the error term. We address the first challenge by including a set of twenty dummies representing each vigintile of per capita non-green ARRA. This allows us to compare the effect of green ARRA in communities that received similar levels of non-green ARRA investments and to test the robustness of our results to 
the exclusion of vigintiles in which the dispersion of green ARRA spending is very high or low or for which the correlation between green and non-green ARRA is very high.

Second, the allocation of green investments may be dependent on characteristics of the local economy. In general, ARRA spending targeted areas hardest hit by the recession and is endogenous by construction. The share of ARRA that is green may be further influenced by features of the economy specific to green investments, such as the presence of a federal DOE laboratory or the renewable energy potential of a region. We address these concerns through two sets of control variables. The first set captures the economic conditions in commuting zone $i$ before the great recessions and are quite standard in the literature evaluating the Recovery Act (e.g. Wilson, 2012; Chodorow-Reich et al., 2012; Chodorow-Reich, 2019). The second set of controls are specific to the green economy, such as the stringency of environmental regulation in the local area (Greenstone, 2002), wind and solar energy potential (Aldy, 2013) and the pre-existing base of green skills in each commuting zone (Vona et al., 2018).

Third, we observe that even after controlling for these observables, areas receiving more green ARRA experienced higher employment growth before the great recession. While standard state or regional fixed effects are sufficient to eliminate the pre-trend for non-green ARRA investments, they do not eliminate the pre-trend on total employment for green ARRA. We address these pre-trends in two ways. First, we allow the effect of green ARRA investments to vary across three periods: the pre-ARRA period (2005-2007); the short-term (2009-2012) and the long-term (2013-2017). We compute the long- and short-run effect of green ARRA by subtracting its effect before 2008. Second, we use a standard shift-share instrument (e.g., Nakamura and Steinsson, 2014), where we combine the pre-sample share of different types of green spending in each commuting zone with the green ARRA shift. While neither solution is perfect, comparing the OLS 
and the IV results is very informative, as each approach minimizes a different source of endogeneity. The IV mitigates endogeneity related to non-random assignment of green ARRA subsidies but it represents an upper bound, as it may capture the effect of past green spending on areas that were already on a green path (Jaeger et al., 2018), i.e. compliers in a LATE terminology (Imbens and Angrist, 1994). The OLS does the opposite: the effect should be smaller as it is the average of the exogenous shock on compliers and the endogenous shock on non-compliers. However, it is less likely to conflate the effect of green ARRA with that of past green policies.

Finally, we contribute to the voluminous literature that evaluates the labor market impact of environmental policies. ${ }^{5}$ Our critical contribution rests on the fact that we are the first to evaluate the effect of a green subsidy rather than that of a policy imposing a cost (i.e. an emission standard or a carbon tax). The only exception is the related paper of Vona et al. (2019), which uses similar data. Following Moretti (2010), they estimate the additional number of jobs indirectly created in the local economy by a new green job. We extend their work by estimating the direct effect of green subsidies, its time-profile and the heterogeneous effects across workers, sectors and communities.

We find that green ARRA increases total employment, but that it works more slowly than other stimulus investments. The results from our preferred specification is in the mid-range of previous estimates, with just under 15 jobs created per $\$ 1$ million of green ARRA in the long-run. The persistency of the job creation effect is clearly a positive aspect of the green fiscal stimulus. However, we find little evidence of short-run employment gains. The timing of green ARRRA's impact differs from previous studies of other ARRA investments, which generally find short-term

\footnotetext{
${ }^{5}$ For the evaluation of the effect of the US Clean Air Act see, e.g., Greenstone (2002), Walker (2011), Ferris et al. (2014), Curtis (2018) and Vona et al. (2018). For estimates of the effect of energy prices and carbon taxes, see, e.g., Kahn and Mansur (2013), Martin et al. (2014), Marin and Vona (2017, 2019), Yamzaki (2017) and Yip (2018).
} 
effects. While the unavoidable presence of pre-trends prevents us from drawing firm conclusions on the overall effect of green ARRA, its impact becomes much clearer when we explore several dimensions of heterogeneity, for which pre-trends are less of a concern. Green ARRA creates more jobs in commuting zones with a greater prevalence of pre-existing green skills. As the presence of green skills in a community is also strongly correlated with the allocation of green ARRA subsidies, our results provide evidence of the green stimulus as a successful example of picking winners. Looking at specific sectors of the economy, we see the potential of a green stimulus to reshape an economy and increase the local demand for green tasks. Nearly half of the jobs created by green ARRA investments were in construction or waste management. Nearly all of the new jobs created are manual labor positions. Importantly, while we find evidence of pre-trends when evaluating total employment, we find no evidence of pre-trends when we study heterogeneous impacts across sectors and workers, providing us with confidence that our results are credible. Even though the largest employment gains were for manual laborers with at least some college education, manual labor wages did not increase. These missing wage gains may either reflect the fact that the green stimulus was too small to offset the long-term deterioration of the bargaining power of manual workers, or the poor quality of the jobs created. While further research is required to understand the impact of green subsidies on labour market inequalities, these results suggest that the green stimulus may create new opportunities for those most affected by globalization and automation.

The remainder of the paper is organized as follows. Section 2 gives the necessary background on the green part of the Recovery Act. Section 3 presents the data used for this project as well as preliminary descriptive statistics. Section 4 discusses the empirical strategy, while Section 5 the main results. Section 6 discusses the policy implications of our study. 


\section{The Green component of the Recovery Act}

In response to the Great Recession, the American Recovery and Reinvestment Act (ARRA) of 2009, commonly known as the stimulus package, invested over $\$ 800$ billion in the forms of tax incentives and federal spending programs to stimulate the US economy. Through ARRA spending programs, federal agencies partnered with state and local governments, non-profit and private entities to help "put Americans back to work". Naturally, much of the spending programs funded projects that provide immediate job opportunities, such as highway construction, or filled state budget shortfalls to bail out the school system and save the jobs of teachers and school staff. Figure 1 shows the breakdown of funds by federal agency, which confirms large ARRA spending on education and transportation.

Figure 1 - ARRA spending by awarding Department / Agency

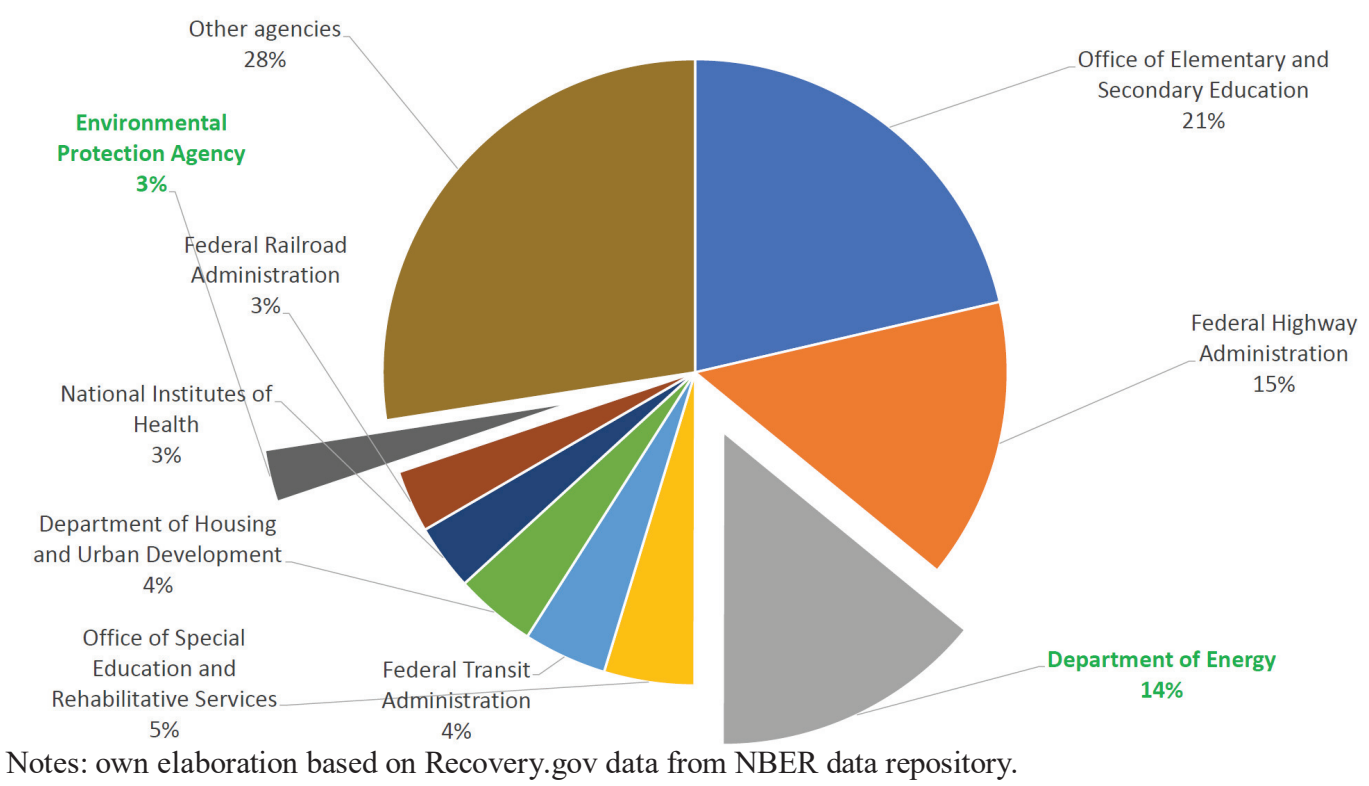


While the primary goal of ARRA was to stimulate macroeconomic growth and provide job opportunities, part of the funds were invested in “... environmental protection, and infrastructure that will provide long-term economic benefits" (American Recovery and Reinvestment Act of 2009). These include both direct spending intended for immediate job creation, such as Department of Energy spending for renewable energy and energy efficiency retrofits and Environmental Protection Agency grants for brownfield redevelopment, as well as tax breaks and loan guarantees for renewable energy. Our work focuses on the impact of direct spending intended for job creation, asking both whether these green investments stimulated employment and what types of workers may benefit from a green stimulus.

Among the key principles motivating infrastructure investments in ARRA was that facilitating the transition to energy efficient and clean energy economy would lay the foundation for long-term economic growth (Office of the Vice President, 2010). As a result, ARRA included more than $\$ 90$ billion for clean energy activities, including $\$ 32.7$ billion in Department of Energy contracts and grants to support projects such as energy efficiency retrofits, the development of renewable energy resources, public transport and clean vehicles, and modernizing the electric grid (Aldy, 2013). To meet the Obama administration's target of doubling renewable energy generation by 2012, DOE provided assistance for a large number of projects related to renewable energy; for example, the Massachusetts Clean Energy Center received \$24.8 million to design, construct and operate a wind turbine blade testing facility (Department of Energy, 2010). Moreover, $\$ 3.4$ billion in cost-shared grants supported the deployment of smart grid technology, generating more than $\$ 4.5$ billion of co-investment (Aldy 2013). ARRA funding also supported the expansion of the Weatherization Assistance Program, which supports low-income families for energy efficiency improvements (Fowlie et al., 2018). 
The Environmental Protection Agency (EPA) oversaw most ARRA programs designated for environmental protection. The largest of these programs was $\$ 6.4$ billion for Clean and Drinking Water State Revolving Funds, which are among the programs analyzed in Dupor and McCrory (2018). An additional $\$ 600$ million was set aside for EPA's Superfund program to clean up contaminated sites such as the New Bedford Harbor site in Massachusetts and the Omaha Lead Site in Nebraska, to which the EPA allocated $\$ 30$ million and $\$ 25$ million, respectively ${ }^{6}$ (Office of the Vice President, 2010). Another \$200 million was invested in the Leaking Underground Storage Tank Trust Fund for the prevention and cleanups of leakage from underground storage tanks. Other EPA funds were allocated to improvements of infrastructures such as wastewater treatment facilities and diesel emissions reduction (Environmental Protection Agency, 2009).

\section{A. Data on ARRA awards}

Our analysis covers the universe of contracts, grants and loans awarded under the ARRA between 2009 and 2012. Recipients of ARRA funding are required to submit reports through FederalReporting.gov, which include information on the amount of expenses and the description of projects. ${ }^{7}$ We retrieved data from FedSpending.org on these records derived from reports submitted by non-federal entities who received ARRA funding.

In line with most recent evaluations of ARRA (Dupor and Mehkari, 2016; Dupor and McCrory, 2018), our unit of analysis is the local labor market, i.e. the so-called commuting zone (CZ). We aggregate county-level data into 709 Commuting Zones based on the official CZ definitions from the 2000 Decennial Census. As in Dupor and Mehkari (2016), we exclude 122

6 Information on active and archived Superfund sites is available at https://cumulis.epa.gov/supercpad/cursites/srchsites.cfm, last accessed May 27, 2020.

${ }_{7}$ This website is no longer use, but archived data are available at https://data.nber.org/data/ARRA/, last accessed March 6, 2020. 
commuting zones with less than 25,000 inhabitants in 2008, which represent less than $0.5 \%$ of the US population and employment. We also drop the commuting zone pertaining to New Orleans, LA, as their employment and population data are heavily influenced by the recovery from Hurricane Katrina. Our primary estimation sample is thus constituted by $587 \mathrm{CZs}$. As the entities known as prime recipients who directly received funding from the federal government may make sub-contracts to other entities, we use the reported place of performance of prime and sub-prime recipients to allocate the dollar amount of awards to commuting zones based on the zip code. ${ }^{8}$

Nearly all DOE and EPA projects relate to the green economy. ${ }^{9}$ Thus, our measure of green ARRA includes all ARRA projects from the DOE and EPA and their subordinate agencies, such as various national laboratories. All other ARRA spending is coded as non-green ARRA. ${ }^{10}$ Table A1 in Appendix A1 provides descriptive data on both green and non-green ARRA. Overall, the stimulus included over $\$ 61$ billion on green investments and $\$ 265.5$ billion on non-green investments. Of these green investments, $\$ 52$ billion come from the DOE, while just $\$ 9$ billion come from EPA. Roughly $10 \%$ of green ARRA spending supported R\&D. A small \$228 million supported job training for green occupations.

\footnotetext{
${ }^{8}$ Unlike other evaluations of ARRA, we do not consider the location of vendors when allocating funds. Our goal is to ascertain the effectiveness of green ARRA given the "greenness" of the local economy. If a recipient must use vendors from outside the local commuting zone to satisfy a need of the project due to a lack of qualified suppliers in the commuting zone, the funding has been less effective for stimulating local employment.

${ }^{9}$ To verify this, we checked projects with the term "oil", "gas", or "coal" in the description. None of these projects related to discovery of new sources. More commonly, they referenced reducing consumption, clean coal, carbon sequestration, or biofuels as a substitute.

${ }^{10}$ In addition to the EPA and DOE, a few other agencies funded investments that were plausibly green. While small (totaling just $\$ 496$ million), the Department of Labor (DOL) supported four job training programs that focused on energy efficiency and the renewable energy industry. Including these as green results in less precise estimates, but does not change the interpretation of our results. While the Department of Housing and Urban Development (HUD) also supported green building retrofits, we did not include these programs in our analysis. These do not fall under a single green program, and thus must be identified manually. In our attempt to label HUD investments as "green", we found that many of the "green" HUD grants were trivial - e.g. installing LED lightbulbs in a building - and should have little to no impact on green employment.
} 
The mean value of green ARRA and non-green ARRA per commuting zone in our sample are \$103 million and \$442 million dollars, respectively, so that green ARRA is slightly overrepresented in our sample relative to the data provided in Figure 1. The per-capita level of green ARRA and non-green ARRA are \$260 and \$988, respectively, based on population in 2008. We highlight the skewed distribution of both green and non-green ARRA, as the median commuting zone received only $\$ 105$ and $\$ 821$ dollars per capita of green and non-green ARRA awards.

Figures A1, A2 and A3 in Appendix A1 illustrate the geographic distribution of green ARRA and non-green ARRA. We do not observe any apparent, systematic patterns across geographic areas, as both areas receiving high per capita amounts (Figures A1 \& A2) and areas receiving large shares of green stimulus (Figure A3) are spread throughout the country (see Table A2 for a list of commuting zones that received the largest ARRA). Figure 2 shows the correlation between green (y-axis) and non-green (x-axis) ARRA expenditure per capita for commuting zones with at least 25000 inhabitants. The bivariate correlation between the two components of ARRA is positive and somewhat strong (0.339). As such, controlling for non-green stimulus spending in a flexible way is important to accurately estimate the impact of green stimulus spending. We discuss our technique for doing so in section IV. 
Figure 2 - Correlation between green and non-green ARRA per capita

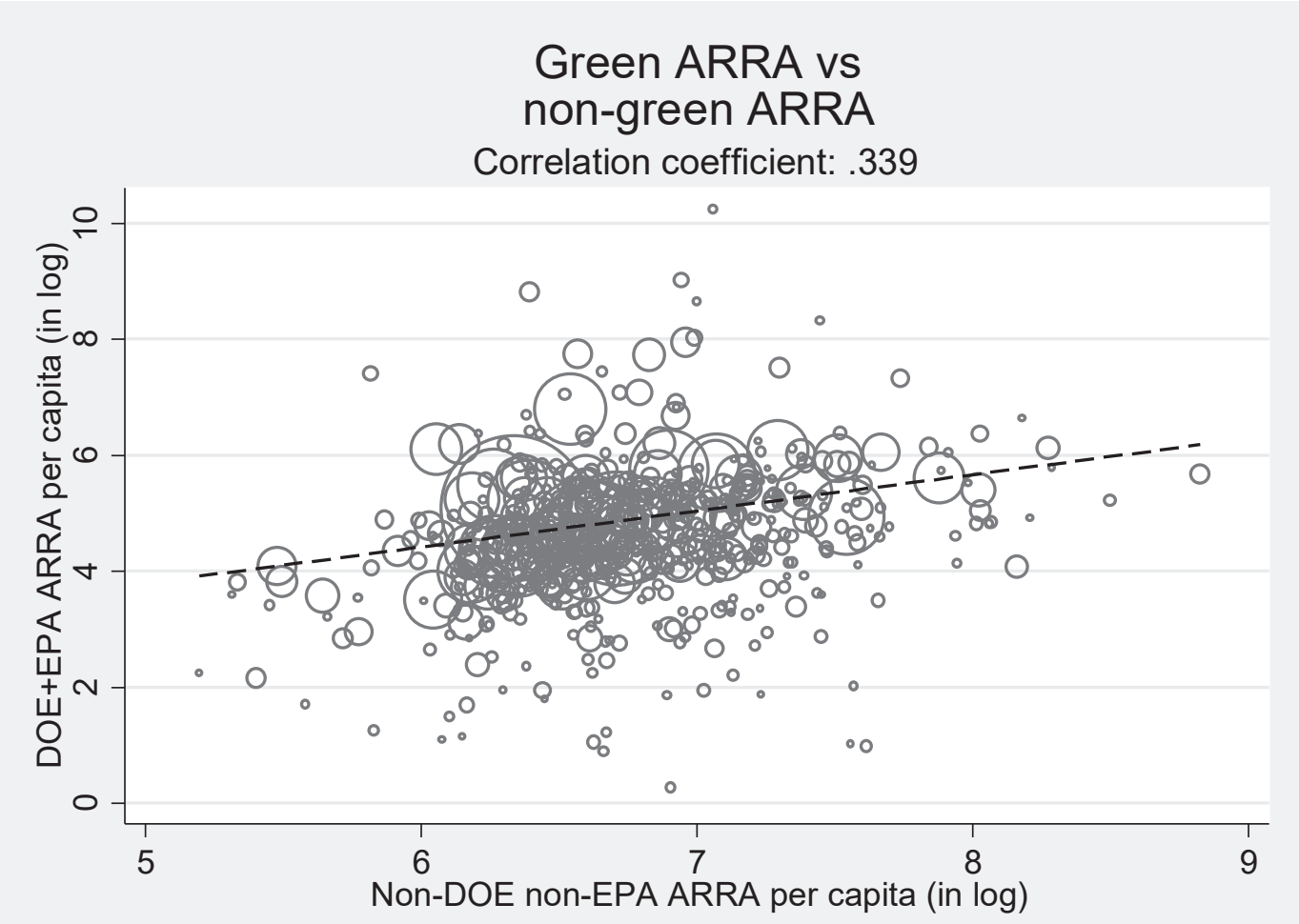

Notes: per capita analysis based on the population of each commuting zone prior to the recession, in 2008. Linear fit and correlation coefficient weighted by CZ population in 2008. Sample: CZ with at least 25000 inhabitants.

\section{Data and Descriptive Statistics}

\section{A. Data}

We combine the ARRA data with data on local labor market conditions. These data include several control variables designed to serve two purposes. Some controls describe each commuting zone's potential exposure and resilience to the Great Recession. Others capture the stringency of environmental policies in the local labor market as well as the relative importance of green versus non-green employment in the local economy. Here we briefly describe our data on employment and green skills. Our additional outcome and control variables in the empirical analysis are collected from standard sources and are described in Appendices A2 and A3. 
Data on total employment and employment by industry were retrieved from the Quarterly Census of Employment and Wages by the Bureau of Labor Statistics (QCEW-BLS). These data report average annual employment by US county and by industry. Data on the occupational composition of employment by $\mathrm{CZ}$ are collected from the $1 \%$ sample of the US population of the annual American Community Survey (ACS), available at IPUMS (Integrated Public Use Microdata Series, Ruggles et al., 2020). Occupation-level data for working-age population (16-64 years old) are used to build our indicators of occupational composition of the workforce.

Our measures of green employment and green skills are based on Vona et al. (2018). For each occupation, the $\mathrm{O}^{*}$ NET database provides the tasks expected of workers and the skills needed to complete these tasks. Tasks are further divided into 'general' tasks, which are common to all occupations, and 'specific' tasks that are unique to individual occupations. The greenness of each occupation is the share of specific tasks that are green (see also Dierdorff et al., 2009, and Vona et al., 2019). Computing the average of occupational greenness (weighted by sampling weights and annual hours worked) for each commuting zone provides the number of full time equivalent green workers in each commuting zone.

Using O*NET data on the importance of general skills to each occupation, Vona et al. (2018) identify a set of green general skills (GGS, hereafter "green skills") that are potentially used in all occupation, but are particularly important for occupations with high greenness. They aggregate this set of selected green skills into 4 macro-groups: Engineering and Technical, Operation Management, Monitoring, and Science. To assess the existing base of green skills, for each occupation we first compute a unique indicator of GGS as the simple average of these four macro groups. Then, using the distribution (weighted by hours worked) of green skills across different (448) occupations in 2000 (IPUMS 5\% sample of the Decennial Census), we identify the 
occupations with green skills importance in the $75^{\text {th }}$ percentile or higher across all US workers. This includes 113 occupations, which are listed in Table A3 in Appendix A2. Consistent with the types of skills included in Green General Skills, these occupations include many scientific and engineering occupations. However, not all jobs using Green General Skills are "green jobs." Green General Skills are also important in occupations such as physicians, mining machine operators, and some transportation workers. The key point is that workers in these jobs have the skills necessary to do the work required of green occupations. We compute the local green skills base in each commuting zone using microdata from the annual American Community Survey (ACS, years 2005-2017, 1\% sample of the US population) from IPUMS. For each commuting zone and year, we calculate the share of total employees (weighted by sampling weights and annual hours worked) in jobs at the top quartile of green skills importance.

\section{B. Descriptive evidence}

To motivate our empirical analysis, here we provide evidence on the relationship between ARRA spending and per-capita employment growth, rescaled by the population of the CZ in 2008. Figures 3 and 4 explore simple unconditional correlations between, respectively, green and nongreen ARRA (2009-2012) per capita and employment growth rate for three different time windows: 2005-2008 (pre-ARRA), 2008-2012 (short term), and 2008-2017 (long term). Overall, we see a positive but very weak correlation between ARRA spending per capita (both green and non-green) and pre-ARRA employment growth across different commuting zones. This positive correlation suggests that the distribution of ARRA spending was not fully random, and that more stimulus funds may have been awarded to commuting zones less in need of assistance. We test this

relationship between stimulus spending and pre-recession employment growth more formally further in our regression analysis. 
The unconditional correlations between ARRA spending per capita and employment growth remain weak even in the short run (2008-2012) and in the long-run (2008-2017). However, it interesting to note that while in the short run the positive correlation between employment growth and ARRA is stronger for the non-green component of ARRA (0.137) than for the green component (0.069), in the longer run the opposite is found. Green ARRA has a positive correlation (0.118) with long run employment growth, while non-green ARRA has a weakly negative correlation (-0.054). While the goal of stimulus spending was to create jobs quickly, green ARRA may have been less effective at rapid job creation. In contrast, green ARRA seems more effective in strengthening local labor markets in the long-run. We will explore this further in our regression analysis.

Figure 3- Green ARRA per capita local spending and employment growth

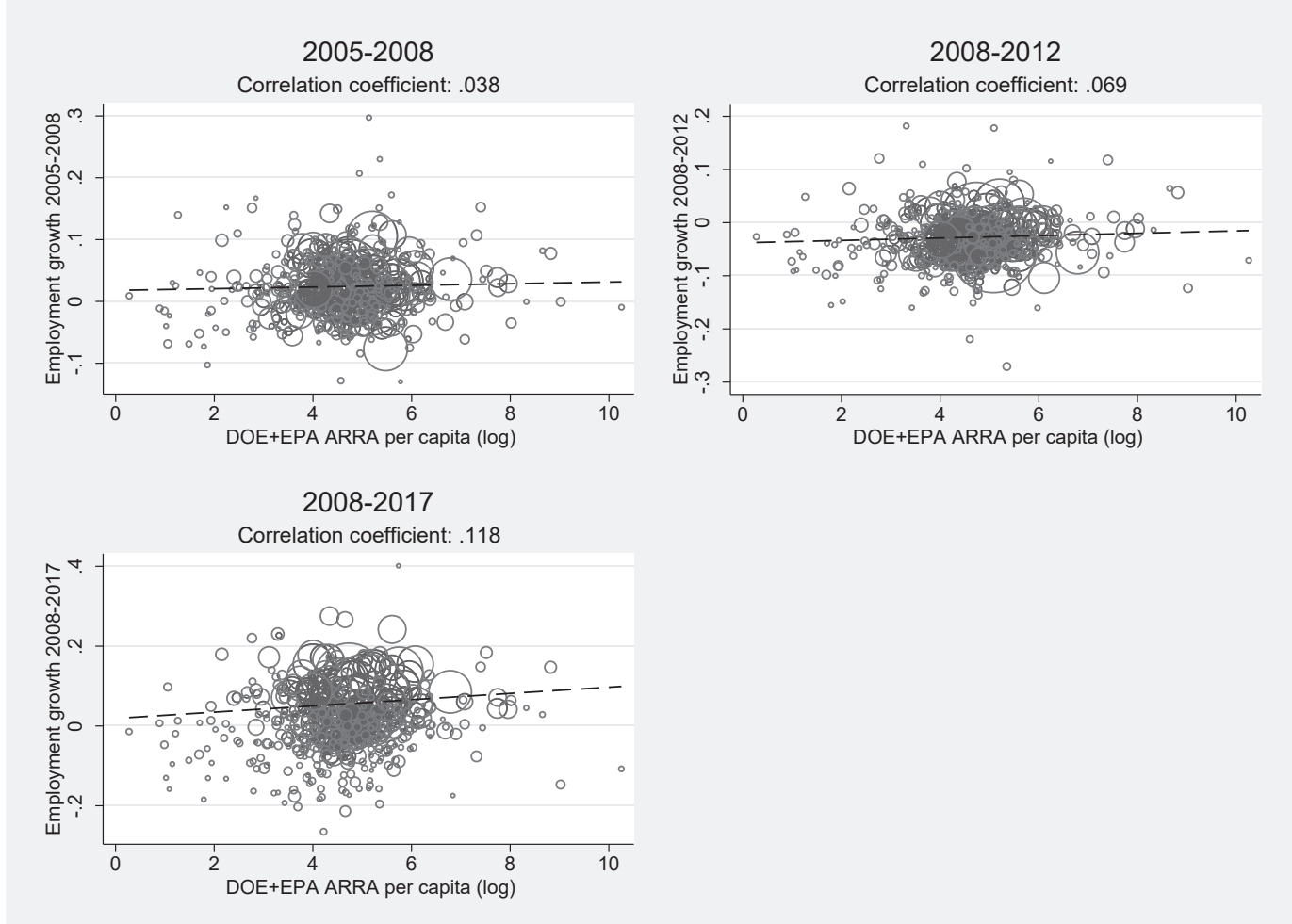

Notes: change in log employment per capita (population of 2008) on log per capita green ARRA. Linear fits and correlation coefficients weighted by CZ population in 2008. Sample: CZ with at least 25000 inhabitants. 
Figure 4- Non-green ARRA per capita local spending and employment/income growth
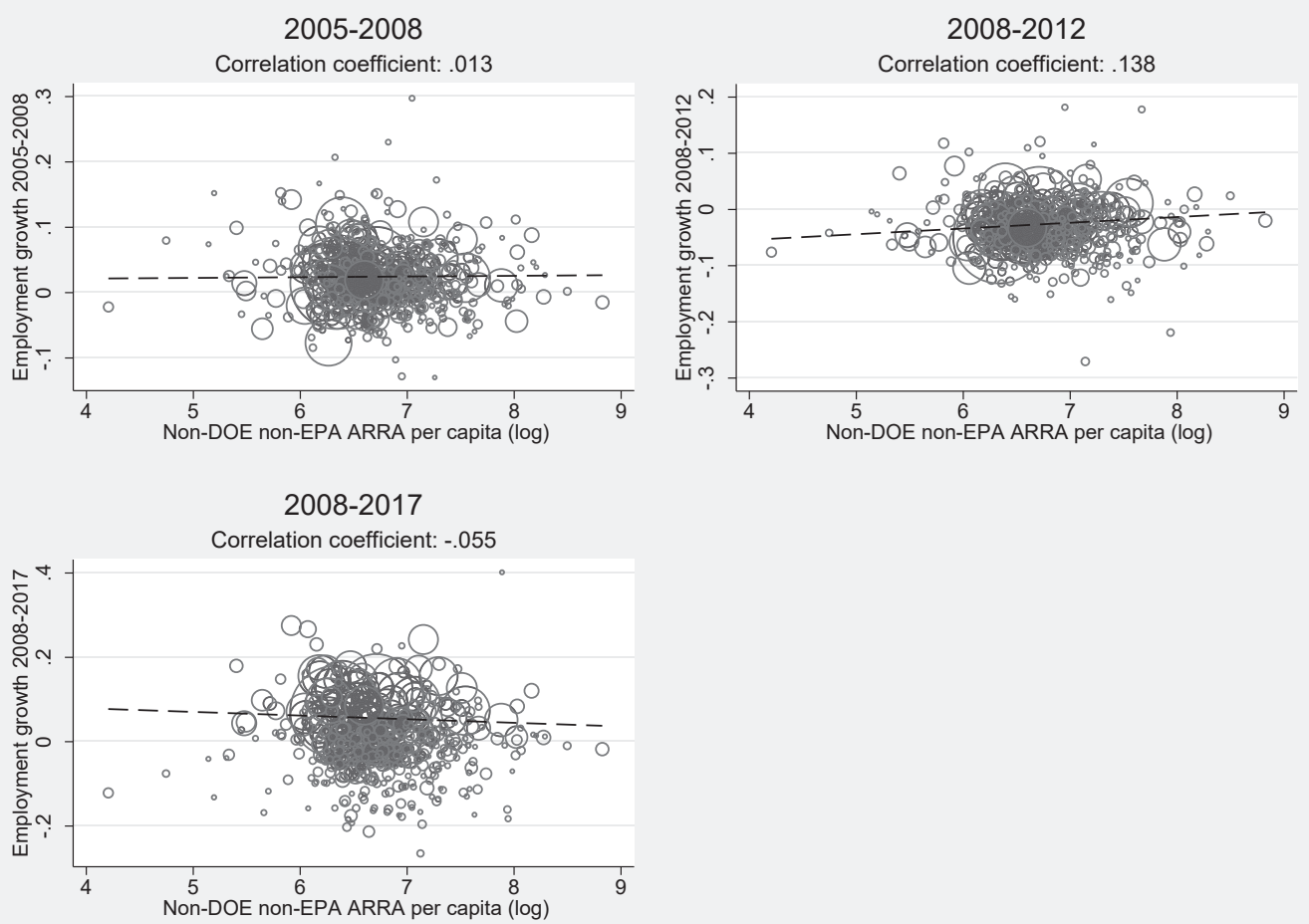

Notes: change in log employment per capita (population of 2008) on log per capita non-green ARRA. Linear fits and correlation coefficients weighted by CZ population in 2008. Sample: CZ with at least 25000 inhabitants.

\section{Empirical Strategy}

This section is organized as follows. Subsection A introduces the main endogeneity issues to estimate the effect of green ARRA on employment. Subsection B discusses our approach to tackle them, while Subsection C presents key extensions to highlight the mechanisms through which green spending affects the local economy.

\section{A. Illustrating endogeneity issues}

ARRA spending has been primarily designed to mitigate the effects of the great recession on local labor markets. Thus it targets areas hardest hit by the recession and is endogenous by construction. For green ARRA, identification is complicated by the presence of an additional 
source of endogeneity. Given the significant share of green ARRA spending devoted to long-term investments and research, the allocation of such spending may have followed criteria related to other structural features of the local economy such as the presence of a federal R\&D laboratory or high-tech manufacturing.

To illustrate the difference in the allocation of green and non-green ARRA, we examine the distribution of the two types of spending along the non-green ARRA distribution. Figure 5 reports the deviations from the mean and the standard deviation of green and non-green ARRA spending per capita relative to the national mean for each vigintile of non-green ARRA spending per capita. Since non-green ARRA has been directed to areas hardest hit by the recession, the Figure illustrates the extent to which green ARRA has been allocated following a different criterion. The left panel of Figure 5 shows that the positive correlation between green and nongreen ARRA masks substantial variation across vigintiles as we observe CZs with low non-green ARRA and high green ARRA or vice versa. In addition, the right panel suggests that the standard deviation of green ARRA within each vigintile is very similar across vigintiles with the exception of the first two vigintiles of non-green ARRA spending and a vigintile in the middle (the $14^{\text {th }}$ ). In our econometric analysis, we will use twenty dummies for non-green ARRA vigintile to make sure that the effect of green ARRA is not capturing that of other ARRA programs. This particular functional form to treat non-green ARRA allows testing the robustness of our results to the exclusion of vigintiles in which the dispersion of green ARRA spending is very high or low or the correlation with non-green ARRA very high. 
Figure 5 - Green ARRA per capita (average and SD) by vigintile of non-green ARRA per capita

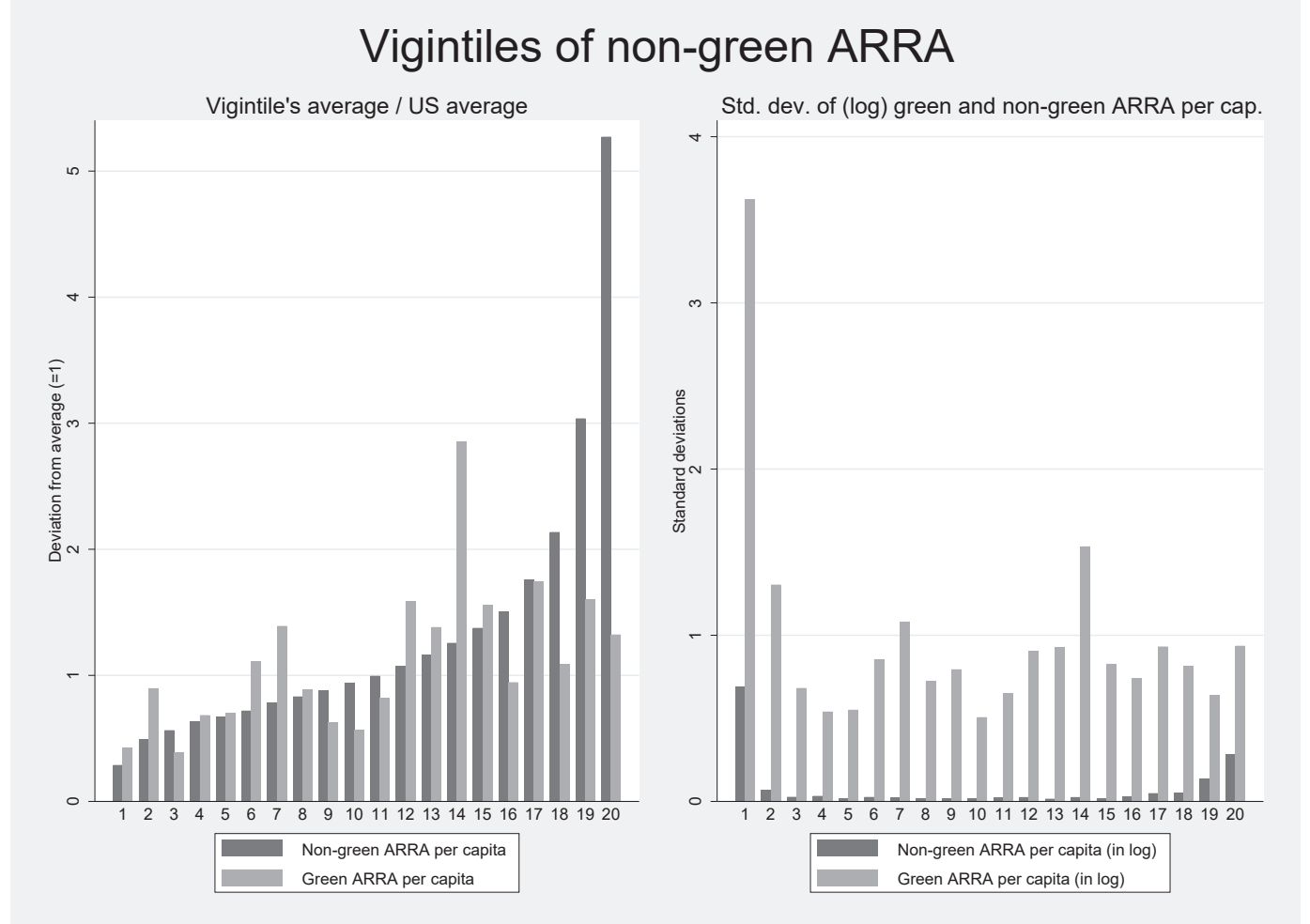

Notes: unweighted vigintiles of non-green ARRA per capita across all CZ. Within-vigintiles average and SD is weighted by $\mathrm{CZ}$ population in 2008.

Next, we directly explore the observable characteristics of a CZ that are associated with green ARRA spending. Strong unbalances in the observable characteristics of CZs receiving different amount of green ARRA are a red spy of an unbalanced distribution also in unobservables (Altonji et al., 2005). We consider the association between the log of green ARRA spending per capita and two sets of covariates that will be used also as controls in our econometric model presented in the next section. The first set captures the economic conditions in commuting zone $i$ before the great recessions and are quite standard in the literature evaluating the Recovery 
Table 1 - Drivers of green ARRA

\begin{tabular}{|c|c|c|c|c|}
\hline Dep var: Green (EPA+DoE) ARRA per capita (in log) & $(1)$ & $(2)$ & (3) & $(4)$ \\
\hline \multirow[t]{2}{*}{ Share of empl with GGS >p75 (year 2006) } & $5.126 * *$ & $4.309 * *$ & $5.157 * *$ & $4.338 * *$ \\
\hline & $(2.384)$ & $(1.992)$ & $(2.444)$ & $(2.059)$ \\
\hline \multirow[t]{2}{*}{ Population $2008(\log )$} & 0.0631 & 0.0676 & 0.0841 & 0.000701 \\
\hline & $(0.0828)$ & $(0.0757)$ & $(0.113)$ & $(0.0950)$ \\
\hline \multirow[t]{2}{*}{ Income per capita (2005) } & $-0.0260^{*}$ & -0.0171 & -0.0118 & 0.00204 \\
\hline & $(0.0142)$ & $(0.0128)$ & $(0.0194)$ & $(0.0142)$ \\
\hline \multirow{2}{*}{ Import penetration (year 2005) } & -2.565 & -5.184 & -10.56 & -16.96 \\
\hline & $(12.80)$ & $(10.67)$ & $(11.52)$ & $(11.76)$ \\
\hline \multirow[t]{2}{*}{ Pre-trend (2000-2007) employment tot / pop } & 0.613 & -0.184 & 0.882 & -0.828 \\
\hline & $(4.272)$ & $(3.973)$ & $(6.298)$ & $(5.485)$ \\
\hline \multirow{2}{*}{ Pre-trend (2000-2007) empl manufacturing / pop } & -8.037 & -6.889 & -6.160 & -7.519 \\
\hline & $(7.168)$ & $(6.894)$ & $(9.011)$ & $(8.558)$ \\
\hline \multirow[t]{2}{*}{ Pre-trend (2000-2007) empl constr / pop } & -13.52 & -10.72 & -5.167 & -15.58 \\
\hline & $(14.04)$ & $(14.97)$ & $(20.08)$ & $(20.22)$ \\
\hline \multirow[t]{2}{*}{ Pre-trend (2000-2007) empl extractive / pop } & -2.723 & 3.551 & -5.929 & 6.103 \\
\hline & $(13.16)$ & $(14.13)$ & $(13.34)$ & $(15.46)$ \\
\hline \multirow{2}{*}{ Pre-trend (2000-2007) empl public sect / pop } & 1.035 & -4.232 & 3.009 & -2.751 \\
\hline & $(10.30)$ & $(8.758)$ & $(12.00)$ & $(9.736)$ \\
\hline \multirow[t]{2}{*}{ Pre-trend (2000-2007) unempl / pop } & 10.66 & 4.025 & -5.376 & -16.73 \\
\hline & $(16.06)$ & $(16.84)$ & $(25.90)$ & $(27.21)$ \\
\hline \multirow[t]{2}{*}{ Pre-trend (2000-2007) empl edu health / pop } & 6.522 & 2.109 & 4.534 & 1.726 \\
\hline & $(5.124)$ & $(4.807)$ & $(6.778)$ & $(5.927)$ \\
\hline \multirow[t]{2}{*}{ Empl manuf (average 2006-2008) / pop } & 5.320 & $4.865^{*}$ & $8.921 * *$ & $7.613 * *$ \\
\hline & $(3.584)$ & $(2.821)$ & $(4.126)$ & $(3.442)$ \\
\hline \multirow[t]{2}{*}{ Empl constr (average 2006-2008) / pop } & $45.61 * * *$ & $48.70 * * *$ & $38.98 * *$ & $37.28 * * *$ \\
\hline & $(13.74)$ & $(11.60)$ & $(14.84)$ & $(13.16)$ \\
\hline \multirow{2}{*}{ Empl extractive (average 2006-2008) / pop } & 6.592 & 2.528 & 4.992 & 2.840 \\
\hline & $(10.65)$ & $(8.414)$ & $(9.408)$ & $(7.291)$ \\
\hline \multirow[t]{2}{*}{ Empl public sect (average 2006-2008) / pop } & $14.46^{*}$ & 4.984 & $22.68 * *$ & $15.11 *$ \\
\hline & $(7.632)$ & $(6.987)$ & $(8.963)$ & $(8.329)$ \\
\hline \multirow[t]{2}{*}{ Unempl (average 2006-2008) / pop } & 21.80 & 20.67 & 12.29 & 18.56 \\
\hline & $(22.04)$ & $(13.36)$ & $(29.08)$ & $(22.32)$ \\
\hline \multirow[t]{2}{*}{ Empl edu health (average 2006-2008) / pop } & 1.867 & 1.382 & 0.557 & 2.119 \\
\hline & $(3.606)$ & $(2.284)$ & $(4.053)$ & $(3.152)$ \\
\hline \multirow{2}{*}{ Shale gas extraction in $\mathrm{CZ}$} & 0.133 & $0.249 * *$ & 0.0169 & 0.118 \\
\hline & $(0.143)$ & $(0.119)$ & $(0.186)$ & $(0.150)$ \\
\hline \multirow[t]{2}{*}{ Potential for wind energy } & -0.0501 & -0.0731 & -0.117 & -0.0937 \\
\hline & $(0.117)$ & $(0.128)$ & $(0.166)$ & $(0.168)$ \\
\hline \multirow[t]{2}{*}{ Potential for photovoltaic energy } & 0.0399 & 0.120 & -0.0261 & 0.0903 \\
\hline & $(0.105)$ & $(0.0927)$ & $(0.192)$ & $(0.163)$ \\
\hline Federal R\&D lab & $0.459 * *$ & $0.420 * *$ & 0.448 & $0.560 * *$ \\
\hline & $(0.212)$ & $(0.206)$ & $(0.286)$ & $(0.236)$ \\
\hline CZ hosts the state capital & 0.285 & -0.0202 & 0.119 & -0.136 \\
\hline & $(0.180)$ & $(0.190)$ & $(0.229)$ & $(0.235)$ \\
\hline Nonattainment CAA old standards & -0.0943 & -0.173 & -0.212 & -0.177 \\
\hline & $(0.170)$ & $(0.165)$ & $(0.190)$ & $(0.202)$ \\
\hline Nonattainment CAA new standards & 0.106 & 0.0820 & 0.202 & 0.227 \\
\hline & $(0.136)$ & $(0.125)$ & $(0.188)$ & $(0.174)$ \\
\hline US-Division dummies & Yes & Yes & No & No \\
\hline State dummies & No & No & Yes & Yes \\
\hline Vigintiles of non-green ARRA per capita & No & Yes & No & Yes \\
\hline R squared & 0.279 & 0.373 & 0.336 & 0.419 \\
\hline $\mathrm{N}$ & 587 & 587 & 587 & 587 \\
\hline
\end{tabular}


Act (e.g. Wilson, 2012; Chodorow-Reich et al., 2012; Chodorow-Reich, 2019). ${ }^{11}$ The second set of variables are more specific to the green economy such as the stringency of environmental regulation in the local area (Greenstone, 2002), wind and solar energy potential (Aldy, 2013) and the index of the green capabilities of the workforce described in section III.A (Vona et al., 2018). ${ }^{12}$

Table 1 shows that the inclusion of the vigintiles of non-green ARRA is not enough to eliminate differences in observable characteristics that are significantly correlated with the intensity of green ARRA spending per capita. The Table also highlights the different sources of endogeneity in the allocation of green ARRA: CZs receiving more green subsidies are both stronger in terms of technological expertise (workforce skills for the green economy, higher share of manufacturing employment and the presence of a federal R\&D lab) and weaker in terms of economic performance (lower average income per capita and higher share of employment in construction, that was particularly badly hit by the great recession).

${ }^{11}$ We consider both the level and the pre-trends (2005-2007) in several variables such as total employment, unemployment and employment in different sectors. As in Wilson (2012), we include the pre-sample level (average 2006-2008) and long pre-trends (2000-2007) for the following variables: total employment, employment in health, public sector and education, employment in manufacturing, construction and extraction, unemployment. We also add other confounders of local labor market conditions such as pre-sample income per capita, a dummy equal one for $\mathrm{CZ}$ with positive shale gas production and import penetration. See data Appendix A2 for details on data sources and construction of these variables.

${ }^{12}$ As in Greenstone (2002), we use changes in the attainment status to National Ambient Air Quality Standards (NAAQS) for the six criteria air pollutants defined by the US Clean Air Act (CAA). We classify as nonattainment commuting zones in which at least $1 / 3$ of the population resides in nonattainment counties. We also add a dummy variable to identify areas with nonattainment status for at least one of the NAAQS in 2006 and that therefore were already exposed to stringent CAA regulation. Since wind and solar energy received other types of support from the federal and state governments, including tax credits and loan guarantees as part of ARRA (Aldy, 2013), we add proxies for the wind and solar potential interacted by year fixed effects. We include a dummy equal one for areas hosting a public R\&D lab and the log of local population as Vona et al. (2019) shows that is highly correlated with the size of the green economy in metropolitan areas. Finally, to proxy for the green capabilities of each CZ, we add the share of workers using intensively green general skills, i.e. skills most relevant in green jobs (see Vona et al., 2018 for details on the green skill measures). This is computed as the share of workers in the local workforce above the $75^{\text {th }}$ percentile of the national distribution of green skills in 2006. See data Appendix A2 for details on data sources and construction of these variables. 
Columns (4)-(6) of Table 2 show that the issue of pre-trends is specific to green stimulus spending. Here, we replace the vigintiles of per capita non-green ARRA with a continuous measure of per capita non-green ARRA (in logs). State fixed-effects are sufficient to remove the pre-trend for non-green ARRA spending. Yet the results for green ARRA remain the same: pre-trends are strongest when including state fixed effects. A likely explanation for this finding is that many ARRA funds were allocated as block grants to states using pre-existing formulas. As such, the allocations to states are plausibly exogenous (e.g. Wilson, 2012). However, states have discretion as to how to allocate these block grants within the state. For instance, states could have prioritized allocating green ARRA block grant funds to commuting zones that were already "green". Our results suggest that such targeting of stimulus spending to well-performing areas by state governments was the case for green stimulus spending, but not for non-green stimulus spending. State fixed effects identify the effects of ARRA based on within-state variation only, which is not necessarily exogenous. Division dummies allow for a broader comparison group that is more likely to be exogenous. Using census division fixed effects, rather than state fixed effects, reduces but does not eliminate the pre-trends for green ARRA. For this reason, we use division dummies in our preferred empirical specification.

While the role of unbalances in the covariates can be mitigated by directly testing the robustness of the results to the exclusion of areas with shale gas production or R\&D labs, the presence of pre-trends requires greater care to provide an accurate estimate of the effect of green ARRA on employment. We discuss the possible solution to this problem in the next section.

\section{B. Estimating equation and instrumental variable strategy}

Our main econometric model is an event-study model that jointly estimates the effects of green ARRA for years before and after the crisis. The first main advantage of this approach is that 
we can explicitly tackle the issue of pre-trends discussed above. The second advantage is being able to assess whether the effect of green ARRA lasts beyond the stimulus period, possibly generating a virtuous circle of green investments. Our dependent variable is the long-difference between our measures of per-capita employment in year $t$ relative to our base year of $2008 .{ }^{13}$ So that the value can always be interpreted as growth in employment, we define the dependent variable as follows:

$$
\begin{array}{ll}
\Delta \ln \left(y_{i, t}\right)=\ln \left(\frac{y_{i, 2008}}{\text { pop }_{i, 2008}}\right)-\ln \left(\frac{y_{i, t}}{\text { pop }_{i, 2008}}\right)=\ln \left(\frac{y_{i, 2008}}{y_{i, t}}\right) & \text { if } \mathrm{t}<2008 \\
\Delta \ln \left(y_{i, t}\right)=\ln \left(\frac{y_{i, t}}{\text { pop }_{i, 2008}}\right)-\ln \left(\frac{y_{i, 2008}}{\text { pop }_{i, 2008}}\right)=\ln \left(\frac{y_{i, t}}{y_{i, 2008}}\right) & \text { if } \mathrm{t}>2008
\end{array}
$$

Using this, we estimate the following equation for the 587 commuting zones in our primary estimation sample:

$$
\Delta \ln \left(Y_{i t}\right)=\alpha+\sum_{t} \beta_{t} \ln \left(\frac{\operatorname{GreenARRA}_{i}}{\operatorname{pop}_{i, 2008}}\right)+\sum_{t} \mathbf{X}_{i t_{0}}^{\prime} \boldsymbol{\varphi}_{t}+\sum_{t} \mathbf{G}_{i t_{0}}^{\prime} \boldsymbol{\varphi}_{t}+\mu_{i \in v, t}+\eta_{i \in c, t}+\epsilon_{i t}
$$

where $\epsilon_{i, t}$ is an error term, $\mu_{i \in v, t}$ are period-specific dummies for the vigintiles of non-green ARRA spending and $\eta_{i \in c, t}$ are period-specific region fixed effects, i.e. census division fixed effects in our preferred model and state fixed effects in an alternative specification.

Importantly, we estimate equation (1) by stacking all years together, but we allow the coefficient of green ARRA and of all the other covariates, including region fixed effects and the vigintiles for non-green ARRA to vary only among three periods: the pre-ARRA (2005-2007); the short-term (2009-2012) and the long-term (2013-2017). This reduces the number of coefficients to be estimated which is important to assess the role of mediating factors of green ARRA effects,

\footnotetext{
${ }^{13}$ Employment is either green employment, total employment or employment in a particular sector (construction, manufacturing, etc.) or occupation (managers, manual workers, etc.). See Appendix A3 for more details on data sources and measurement of our dependent variables.
} 
such as availability of the right know-how in the local labor market. To visually convey our main result, we also plot the green ARRA coefficients estimated on a yearly frequency through equation (1).

The main variable of interest is green ARRA spending, also rescaled by total population in 2008. While effective green spending spanned several years between 2009 and 2012, nearly all outlays were announced in 2009 (see, e.g. Figure 2 in Wilson, 2012). Therefore, we build a time invariant measure of green spending as the total spending across those four years.

We take a log transformation for both our dependent and main explanatory variable to account for the skewness in their respective distributions. In all regressions, we cluster standard errors at the state-level, using the state of the main county in each commuting zone. We cluster at the state level because of the discretion that state governments have allocating ARRA funds. This results in slightly more conservative standard errors than if we cluster at the commuting zone level. We weight observations using population level in 2008.

Given the unavoidable presence of pre-trends documented earlier, we cannot assume that the allocation of green ARRA spending to commuting zones is quasi-random, even after including a rich set of controls given the unbalances in the covariates shown in Table 1. The pre-trend effect $\hat{\beta}_{\text {pre }}$ reflects the presence of unobserved variables that are correlated with both the allocation of green ARRA and the outcome variables. Thus, we compute the long- and short-term effect of green ARRA by subtracting its effect before 2008 . That is: $\hat{\beta}_{\text {short }}-\hat{\beta}_{\text {pre }}$ and $\hat{\beta}_{\text {long }}-\hat{\beta}_{\text {pre }}$ can be interpreted as the average effect of green ARRA in the short- or long-run, respectively.

The credibility of such differences to estimate the effect of green ARRA rests upon an untestable assumption regarding the functional form of the relationship between employment and green ARRA. More specifically, interpreting these differences as average short-run or long-run 
effects assumes that employment trends (and pre-trends) across different commuting zones are affected by observable and unobservable covariates in a linear way. As such, the pre-trend in the effect of green ARRA accurately approximates the counterfactual employment dynamics conditional on all covariates, in commuting zones receiving a larger fraction of green ARRA. For instance, the amount of green ARRA received may be a function of the pre-existing size of the green economy or past government policies in each commuting zone.

As an alternative identification strategy, we exploit the well-known fact that ARRA spending was allocated according to formulas that were in use before the passage of the Recovery Act (see the discussion of Chodorow-Reich, 2018). ${ }^{14}$ Importantly, the formulaic instrument has a typical shift-share structure used in the seminal literature on cross-sectional multipliers (e.g. Nakamura and Steinsson, 2014). In previous studies, such instrument satisfies the exclusion restriction of affecting total employment only through ARRA spending because the main source of endogeneity was the local effect of the great recession.

Unfortunately, such an instrumental variables strategy is not as clean in the case of green ARRA, because endogeneity of green ARRA is also related to the persistent effect of pre-ARRA green spending. In this context, we must be careful in the interpretation of the results obtained using a similar shift-share instrument; that is: an instrument that combines the initial "share" of EPA plus DoE spending in the CZ (over total DoE and EPA spending) with the green ARRA "shift". Such instrument adds an exogenous shock in green expenditures to areas that were already receiving larger amount of green spending before ARRA. Again, it is crucial that the pre-recession

\footnotetext{
${ }^{14}$ According to Conley and Dupor (2013), 2/3 of ARRA spending were allocated using such formulaic approach to privilege shovel-ready projects that have an immediate impact on the economy. For instance, spending in road construction, education and health were allocated by the Recovery Act using the formulas in place before the act (Wilson, 2012; Garin, 2018).
} 
effect of green ARRA properly instrumented mimics the effect that pre-ARRA green spending would have had in the long-run. The problem here is similar to that put forward by Jaeger et al. (2018) by noting that shift-share instrument conflates short- and long-term effects. We follow their suggestion and take a "share" far in the past (i.e. an average share of DoE plus EPA spending between 2003 and 2004), under the assumption that the effect of past spending gradually fades away. Moreover, the existence of a clear shock eases the interpretation of the pre-crisis effect of green ARRA, which is similar to the effect of past policy shocks in their setup. However, the effectiveness of this strategy is limited by the difficulties accurately measuring pre-ARRA green spending, as explained in the data Appendix A4.

Overall, both the IV and the OLS solution of the endogeneity problem rest upon the untestable assumption that the pre-crisis effect of green ARRA is a good estimate of the counterfactual employment growth, conditional on the covariates. However, while neither solution is perfect, comparing the OLS and the IV results can be very informative as each approach minimizes a different source of endogeneity. The IV mitigates endogeneity related to non-random assignment of green ARRA subsidies but it represents an upper bound, as it may capture the effect of past and present green ARRA on areas that were already on a green path, i.e. compliers in a LATE terminology (Imbens and Angrist, 1994). The OLS does the opposite: the effect should be smaller as it is the average of the exogenous shock on compliers and the endogenous shock on non-compliers, which is however less likely to conflate the effect of green ARRA with that of past green policies.

Finally, the estimates obtained from the above empirical strategy provide the average effect of green stimulus on total employment. To explore the mechanism through which green stimulus affects employment, we extend our analysis to test for heterogeneous impacts of green spending. 
We do this in three ways. First, we consider whether the existing skill composition in each commuting zone changes the effectiveness of green ARRA. Second, we estimate separate models for different sectors and occupations, to ascertain whether there is heterogeneity across different types of workers. Finally, we assess the distributional effect of green ARRA spending by estimating the green ARRA impact for different broad groups of workers, such as manual labor. This exercise will indicate whether skill-biased shifts in labor demand induced by green ARRA create winners and losers in particular workers' categories.

\section{Results}

This section presents the main results of the paper. Subsection A focuses on the effect of the green stimulus on total employment. In subsection B, we show that the pre-existing level of green skills matters. Subsection C presents results by sector. Subsection D explores the distributional implications of this further, by focusing on the effect of green ARRA on manual labor. Finally, subsection E reports various robustness checks.

\section{A. Results on Total Employment}

Table 3 shows four specifications to compare the OLS (columns 1 and 2) and the instrumental variable (3 and 4) specifications described in section IV.B. We are also interested in comparing how different ways of modeling regional effects influence the results, thus in columns 1 and 3 we use census division dummies and in columns 2 and 4 state dummies. For sake of completeness, the Table reports the point estimates of the green ARRA coefficients for the preARRA period $\left(\hat{\beta}_{\text {pre }}\right)$, the short-term $\left(\hat{\beta}_{\text {short }}\right)$ and the long-term $\left(\hat{\beta}_{\text {long }}\right)$. However, the key statistics

of interest are: $\hat{\beta}_{\text {long }}-\hat{\beta}_{\text {pre }}$ and $\hat{\beta}_{\text {short }}-\hat{\beta}_{\text {pre }}$, which measure the effect of the green stimulus net of the pre-trend. Our comments focus on these statistics as well as on the corresponding number 
of jobs created per millions of dollars spent. Since the quantification of the number of jobs created is not straightforward as in related papers, we report in Appendix B the arithmetic to translate the estimated coefficients into number of jobs created.

We first discuss the selection of a preferred specification among the four presented in the Table. We find that IV results are larger than the OLS ones, especially when using state dummies (column 2 vs. 4). However, the precision of the estimated $\hat{\beta}_{\text {long }}-\hat{\beta}_{\text {pre }}$ difference drops significantly when using census division dummies and the IV (column 3). The lack of precision is not primarily associated with a weak instrument problem (Angrist and Pischke, 2008) ${ }^{15}$ and thus highlights higher heterogeneity in the effect within the compliers. As a further check of the credibility of the IV strategy, we perform an over-identification test on instruments' exogeneity by splitting the IV in its two components: EPA spending and DoE spending (the first-stage results are shown in Table C2 in Appendix C). Goldsmith-Pinkham et al. (2018) propose to use this diagnostic for the standard shift-share instrument which is a linear combination of multiple instruments. We find that only the specification with census division dummies fails to reject the null of hypothesis that the exclusion restrictions are satisfied (Table C3 in Appendix C). This is consistent with our previous observation that, since states have discretion in allocating part of the ARRA funds, controlling for state dummies amplifies the endogeneity problem.

\footnotetext{
15 The instruments are not very strong, but the first-stage is above the usual cut-off threshold of 10 (e.g., 12.7 in column 3 and 13.8 in column 4). The full set of first-stage results is contained in Table C1 of the Appendix C.
} 
Table 3 - Baseline results

\begin{tabular}{|c|c|c|c|c|}
\hline \multirow{2}{*}{ Dep var: Change in log employment per capita compared to 2008} & $(1)$ & $(2)$ & (3) & (4) \\
\hline & OLS & OLS & IV & IV \\
\hline Green ARRA per capita (log) x D2005_2007 & $(0.00105)$ & $(0.000913)$ & $(0.00565)$ & $(0.00432)$ \\
\hline Green ARRA per capita (log) x D2009_2012 & $(0.000845)$ & $(0.000734)$ & $(0.00434)$ & $(0.00312)$ \\
\hline \multirow[t]{2}{*}{ Green ARRA per capita (log) x D2013_2017 } & $0.00523 * * *$ & $0.00500 * * *$ & 0.0129 & $0.0162 * * *$ \\
\hline & $(0.00169)$ & $(0.00132)$ & $(0.00958)$ & $(0.00621)$ \\
\hline \multicolumn{5}{|l|}{ Comparison across periods: } \\
\hline Green ARRA per capita (log): 2009-2012 vs 2005-2007 & $\begin{array}{c}0.0001 \\
(0.00102)\end{array}$ & $\begin{array}{c}-0.0003 \\
(0.000897)\end{array}$ & $\begin{array}{c}-0.00139 \\
(0.00478)\end{array}$ & $\begin{array}{c}0.00077 \\
(0.00337)\end{array}$ \\
\hline \multirow[t]{2}{*}{ Green ARRA per capita (log): 2013-2017 vs 2005-2007 } & $0.00318^{*}$ & 0.00221 & 0.00503 & 0.00946 \\
\hline & $(0.00179)$ & $(0.00160)$ & $(0.00879)$ & $(0.00623)$ \\
\hline $\mathrm{N}$ of jobs created by $\$ 1 \mathrm{mln}$ green ARRA: short term (2009-2012) & 0.44 & -1.29 & -6.02 & 3.36 \\
\hline F-test of excluded IV from first stage & & & 12.72 & 13.80 \\
\hline $\begin{array}{l}\text { F-test of excluded iv from first stage } \\
\text { Observations }\end{array}$ & 7631 & 7631 & 7631 & 7631 \\
\hline \multicolumn{5}{|c|}{$\begin{array}{l}\text { Notes: Regressions weighted by CZ population in 2008. Sample: } 587 \text { CZ with at least 25,000 residents in 2008. Year dummies included. } \\
\text { Additional control variables (interacted with D2002_2007, D2009_2012 and D2013_2017 dummies): Vigintiles of non-green ARRA per capita, } \\
\text { Share of empl with GGS>p75 (2005), Population 2008 (log), Income per capita (2005), Import penetration (year 2005), Pre trend (2000-2007) } \\
\text { empl manufacturing / pop, Pre trend (2000-2007) employment tot / pop, Pre trend (2000-2007) empl constr / pop, Pre trend (2000-2007) empl } \\
\text { extractive / pop, Pre trend (2000-2007) empl public sect / pop, Pre trend (2000-2007) unempl / pop, Pre trend (2000-2007) empl edu health / pop, } \\
\text { Empl manuf (average 2006-2008) / pop, Empl constr (average 2006-2008) / pop, Empl extractive (average 2006-2008) / pop, Empl public sect } \\
\text { (average 2006-2008) / pop, Unempl (average 2006-2008) / pop, Empl edu health (average 2006-2008) / pop, Shale gas extraction in CZ interacted } \\
\text { with year dummies, Potential for wind energy interacted with year dummies, Potential for photovoltaic energy interacted with year dummies, } \\
\text { Federal R\&D lab, CZ hosts the state capital, Nonattainment CAA old standards, Nonattainment CAA new standards. Endogenous variable } \\
\text { (columns } 3 \text { and 4): Green ARRA per capita (log). Excluded IV from the first stage: shift-share IV of ARRA spending by Department/Agency; } \\
\text { local spending share 2001-2004. Standard errors clustered by state in parentheses. * p }<0.1, * * p<0.05, * * * \text { p }<0.01 \text {. }\end{array}$} \\
\hline
\end{tabular}

Our preferred specification in column (1) indicates that the effect of the green stimulus is much stronger in the long- than in the short-run. While definitive explanations for a stronger longrun effect are left for future research, potential explanations include government investments attracting additional private investments in favored green sectors (Mundaca and Ritcher, 2015) as well as administrative delays related the realization of key green programs. ${ }^{16}$ The long-term effect, net of the pre-ARRA trend, implies that the cost per job of the green stimulus is 67,750 dollars.

\footnotetext{
${ }^{16}$ For example, weatherization grants were delayed by (1) requirements that weatherization grants only go to projects paying a "prevailing wage" and (2) completing a National Historic Preservation Trust review of renovation plans affecting historic buildings (https://abcnews.go.com/WN/Politics/stimulus-weatherization-jobs-president-obamacongress-recovery-act/story?id=9780935, last accessed May 14, 2020).
} 
The creation of 1.47 job per $100 \mathrm{~K}$ is in the middle of the range of estimates of papers evaluating other programs of the Recovery Act (Chodorow-Reich, 2019). However, the long-term effect is statistically different from the pre-ARRA effect only at $10 \%$ level (p-value 0.082 ) and in all three alternative specifications it becomes statistically insignificant. As a result, although our preferred estimate appears plausible compared to the previous literature and substantially lower than the estimate of the green stimulus of the Council of Economic Advisors (2014), we cannot firmly conclude that the green stimulus boosted job creation in the long-run when focusing on overall employment.

We subtract $\hat{\beta}_{\text {pre }}$ when interpreting coefficients because the green stimulus was directed to commuting zones with more sustained job growth before 2008. We acknowledge, however, that the length of time span used in our estimates is not symmetric before and after the great recession. Using only three years to estimate the pre-ARRA effect may lead to a misleading estimate of a long-term pre-ARRA pattern. To shed light on this issue and fully track the time profile of the green stimulus, we re-estimate our OLS specifications using data from 2000-2017, allowing all the coefficients of equation (1) to vary yearly. We plot the coefficients as well as the $95 \%$ confidence intervals for green ARRA in Figure 6. For these regressions only, our dependent variable is $\ln \left(\frac{y_{i, t}}{\text { pop }_{i, 2008}}\right)-\ln \left(\frac{y_{i, 2008}}{\text { pop }_{i, 2008}}\right)$ both before and after 2008, so that we can interpret the slope of this plot as the effect of green ARRA on the annualized growth rate in per capita employment between adjacent years. ${ }^{17}$ Most notable in this figure is that the pre-trend we observe (green ARRA going to commuting zones with greater employment growth) begins between 2004

\footnotetext{
${ }^{17}$ That is, each coefficient represents the effect of green ARRA on per capita employment relative to the base year of 2008. Thus, the difference between the point estimate in any two adjacent years is the effect of green ARRA on the annual growth rate of employment between those two years.
} 
and 2005. Prior to that, we observe a flat line, so that while per capita employment in areas receiving more green ARRA was lower than 2008 in the 2000-2004 period, the annualized growth rate of employment in these commuting zones was no different. This helps support our use of the 2005-2007 period for estimating the pre-trend. Overall, this figure shows that green ARRA investments reinforced a positive employment growth pattern that emerged just a few years before the crisis.

Figure 6 - Year-by-year effects

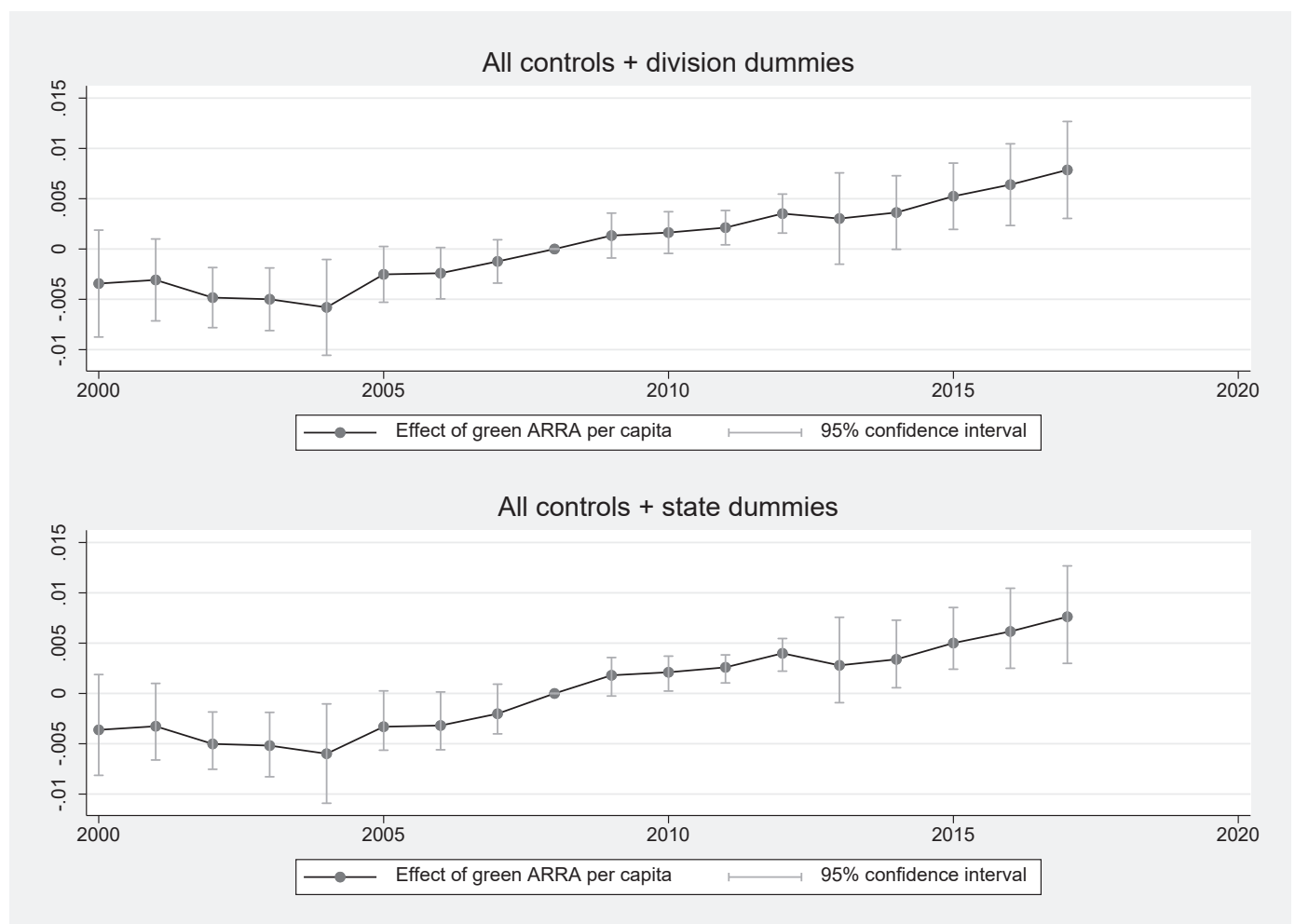

Notes: plot of the annual estimates of $\log$ (per capita green ARRA) on the change in log employment per capita compared to 2008 per capita, using the OLS models weighted by CZ population in 2008 (equation 1).

\section{B. The Mediating Effect of Green Skills}

We next ask whether the effectiveness of green stimulus spending depends on the existing skill base of workers in each commuting zone. The types of skills workers need to work in green jobs may be different than the skills needed in other sectors. We use the data on green skills described in section III to identify the share of employment in each commuting zone in occupations 
with green skills importance in the $75^{\text {th }}$ percentile or higher in 2006 (i.e. prior to the recession). While these jobs need not themselves be green, this captures the local endowment of the types of skills in high demand in a green economy. One might expect green stimulus to be more effective in areas with a higher concentration of green skills.

We augment our baseline model, which already controls for the initial concentration of green skills in a region, by interacting our green ARRA variables (pre-, short- and long-) with the share of employment in occupations with green skills importance in the $75^{\text {th }}$ percentile or higher. Table 4 presents these results, and Figure 7 shows the marginal effect of green ARRA net of the pre-trend at different levels of initial green skills. The results show the importance of the initial skill base. Both $\hat{\beta}_{\text {long }}-\hat{\beta}_{\text {pre }}$ and $\hat{\beta}_{\text {short }}-\hat{\beta}_{\text {pre }}$ becomes statistically significant at the 5 percent level for commuting zones with a sufficiently large base of green skills. Using the specification with census division dummies, the net effect of green ARRA becomes significant for commuting zones with a share of green skills above the cutoff of 0.308 in the short-run and 0.249 in the longrun. ${ }^{18}$ The long-term effect at the last quartile of the GGS distribution is 26 jobs created per $\$ 1$ million (column 1), which is definitely in the upper bound of the range provided by ChodorowReich (2019). The result is even more remarkable by noting the fact that the initial share of occupations in the upper quartile of GGS importance itself has a large effect on future employment growth. Recall from Table 1 that the initial share of occupations in the upper quartile of GGS importance is also strongly correlated with the allocation of green ARRA subsidies. In combination, these results reinforce our interpretation of the green stimulus as a successful example of picking the winners.

\footnotetext{
${ }^{18}$ These thresholds correspond, respectively, to the 97th and 46th percentile of the cross-CZ distribution of our GGS variable.
} 
Table 4 - Interaction with initial green skills

Dep var: Change in log employment per capita compared to 2008

Share of empl with GGS>p75 (year 2006) x D2005_2007

Share of empl with GGS>p75 (year 2006) x D2009_2012

Share of empl with GGS>p75 (year 2006) x D2013_2017

Green ARRA per capita $(\log )$ x D2005_2007

Green ARRA per capita $(\log )$ x D2009_2012

Green ARRA per capita (log) x D2013_2017

Green ARRA per capita (log) x Share of empl with GGS>p75 (year 2006) x D2005_2007

Green ARRA per capita $(\log )$ x Share of empl with GGS $>$ p75 (year 2006) x D2009_2012

Green ARRA per capita $(\log )$ x Share of empl with GGS>p75 (year 2006) x D2013_2017

Comparison across periods and levels of initial GGS:

- First quartile of Share of empl with GGS>p75 (year 2006)

$\mathrm{N}$ of jobs created by $\$ 1 \mathrm{mln}$ green ARRA: short term (2009-2012)

$\mathrm{N}$ of jobs created by $\$ 1 \mathrm{mln}$ green ARRA: long term (2013-2017)

- Median of Share of empl with GGS>p75 (year 2006)

$\mathrm{N}$ of jobs created by $\$ 1$ mln green ARRA: short term (2009-2012)

$\mathrm{N}$ of jobs created by $\$ 1 \mathrm{mln}$ green ARRA: long term (2013-2017)

- Third quartile of Share of empl with GGS>p75 (year 2006)

$\mathrm{N}$ of jobs created by $\$ 1 \mathrm{mln}$ green ARRA: short term (2009-2012)

$\mathrm{N}$ of jobs created by $\$ 1 \mathrm{mln}$ green ARRA: long term (2013-2017)

US-Division dummies $\mathrm{x}$ period dummies

State dummies $\mathrm{x}$ period dummies

R squared

$\mathrm{N}$ of $\mathrm{CZ}$

Observations

Notes: OLS model weighted by CZ population in 2008. Sample: $587 \mathrm{CZ}$ with at least 25,000 residents in 2008. Year dummies included. Additional control variables (interacted with D2002_2007, D2009_2012 and D2013_2017 dummies): Vigintiles of non-green ARRA per capita, Population 2008 (log), Income per capita (2005), Import penetration (year 2005), Pre trend (2000-2007) empl manufacturing / pop, Pre trend (2000-2007) employment tot / pop, Pre trend (2000-2007) empl constr / pop, Pre trend (2000-2007) empl extractive / pop, Pre trend (2000-2007) empl public sect / pop, Pre trend (2000-2007) unempl / pop, Pre trend (2000-2007) empl edu health / pop, Empl manuf (average 2006-2008) / pop, Empl constr (average 2006-2008) / pop, Empl extractive (average 2006-2008) / pop, Empl public sect (average 2006-2008) / pop, Unempl (average 2006-2008) / pop, Empl edu health (average 2006-2008) / pop, Shale gas extraction in CZ interacted with year dummies, Potential for wind energy interacted with year dummies, Potential for photovoltaic energy interacted with year dummies, Federal R\&D lab, CZ hosts the state capital, Nonattainment CAA old standards, Nonattainment CAA new standards. Standard errors clustered by state in parentheses. $* \mathrm{p}<0.1, * * \mathrm{p}<0.05, * * * \mathrm{p}<0.01$. 
Figure 7 - Variation in the Effect of Green ARRA on employment by initial Green Skills
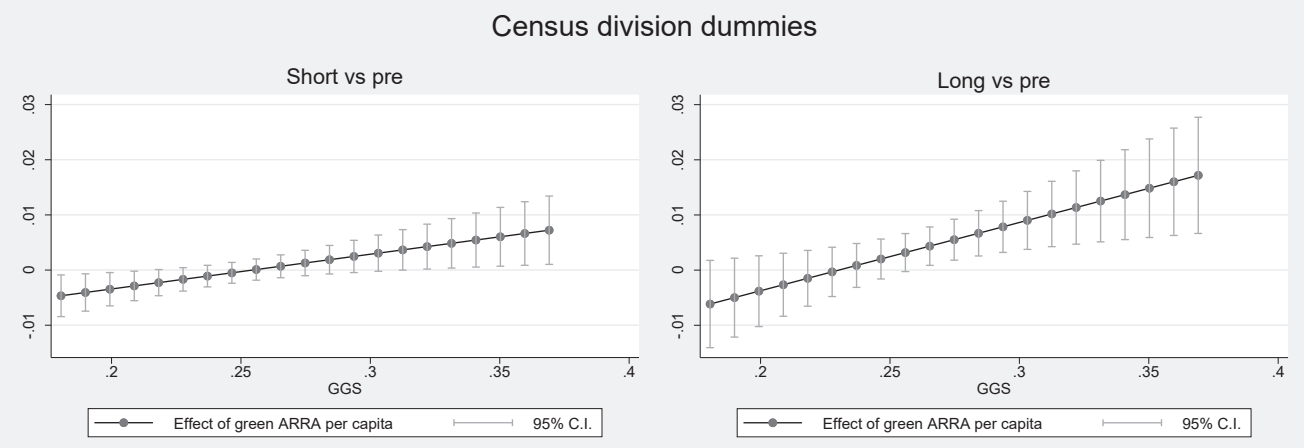

State dummies
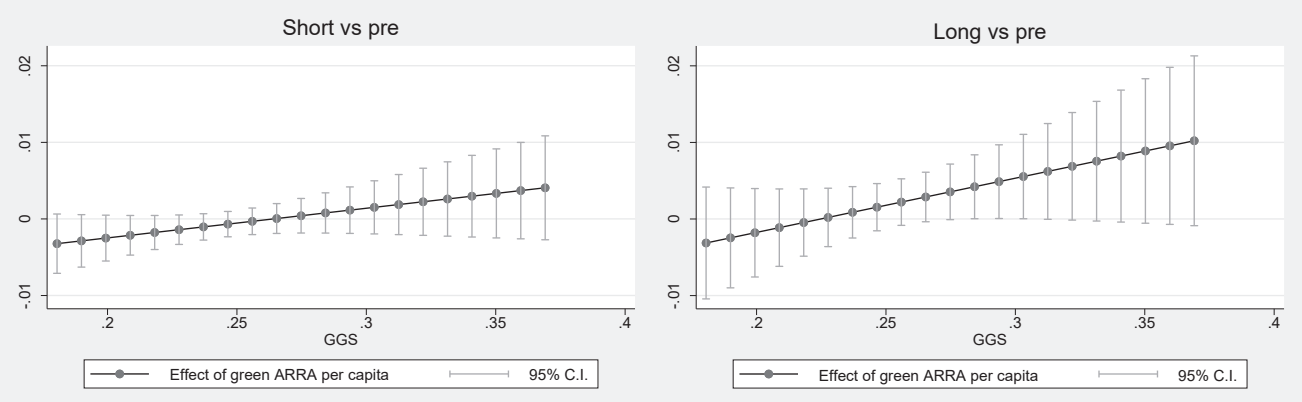

Notes: plot of the marginal effects of green ARRA, conditional on initial Green Skills. Calculations based on estimates from Table 4.

\section{Mechanisms}

In this section, we explore further how the green stimulus affects employment by focusing on specific sectors of the economy. As the effect of the green stimulus is likely to be concentrated in certain sectors, our analysis will shed light on how green policies reshape the structure of the local economy. This exercise provides an initial account of the mechanics through which green ARRA stimulates employment and acts as a validation check that green ARRA really hits these target sectors. Table 5 considers green employment (the share of specific tasks in each occupation that O*NET defines as "green", see Appendix A3 and Vona et al., 2018) and four additional sectors: manufacturing, construction, professional and scientific, and waste management. We focus on green employment, manufacturing, construction and waste management since they are 
the activities are most likely to receive green subsidies. We add professional and scientific services because they make use of Green Skills such as engineering and technical competences that were shown above to enhance the impact of the green stimulus.

As expected, the green stimulus has a positive and statistically significant long-term effect on green employment. While $4.6 \%$ of total employment is green, roughly 20 percent of the jobs created by green ARRA were green. ${ }^{19}$ The additionality effect $\left(\hat{\beta}_{\text {long }}-\hat{\beta}_{\text {pre }}\right)$ is large in absolute term with 2.9 green jobs created per $\$ 1$ million spent, but statistically insignificant at conventional level ( $p$-value $=0.16$ ). Note, however, that the insignificant effect of the joint test is not because green ARRA went disproportionately to regions that had a higher share of green jobs, but rather because of the imprecise negative estimate of the pre-ARRA coefficient. The direct long-run effect is significant at the traditional $5 \%$ level.

The green stimulus also led to job creation in the construction and waste management sectors. Of the 14.8 total jobs created per $\$ 1$ million green ARRA, over half (8.06) are in these two sectors. This is consistent with green ARRA targeting projects such as building renovation for energy efficiency, construction of renewable energy projects (e.g., new wind turbines testing facilities at Clemson University and the Massachusetts Clean Energy Center), and remediation of hazardous waste sites (e.g., a $\$ 5$ million award to support the remediation work at the Vineland Chemical Superfund Site in New Jersey). Once again, pre-trends are less of concern in these sectors, as the coefficients of $\hat{\beta}_{\text {pre }}$ are statistically insignificant. In contrast, we do not find any significant effect on manufacturing, although the long-term effect of green ARRA is positive and significant. In this case, the lack of statistical significance in the additionality effect is associated

\footnotetext{
$194.6 \%$ is slightly higher than the estimate of $3.1 \%$ provided by Vona et al. (2019) for 2014. This can be due to an aggregation bias or to the fact that we add three years after 2014. See Appendix A3 for greater details.
} 
with a positive pre-ARRA effect, meaning that green ARRA reinforced a pre-existing advantage in manufacturing. Moreover, despite our finding that the presence of green skills enhances the effectiveness of green ARRA investments, we find no evidence of increased employment in the professional scientific, and technical services sector.

Overall, the green stimulus reshaped labor markets by increasing the size of the local green economy as well as employment in construction and waste management. However, the distributional effect of the stimulus is less clear. While greener tasks are concentrated in high-skills and thus well-paid occupations (Vona et al., 2019), construction and waste jobs may boost the creation of jobs that pay less. We explore this issue in the next section.

Table 5 - Results by sector

\begin{tabular}{|c|c|c|c|c|c|}
\hline $\begin{array}{l}\text { Dep var: Change in log employment (by type) per capita compared } \\
\text { to } 2008\end{array}$ & $\begin{array}{c}\text { Green } \\
\text { employment } \\
\text { (O*NET-based } \\
\text { definition) }\end{array}$ & $\begin{array}{c}\text { Manufacturing } \\
\text { sector (NAICS } \\
31-33 \text { ) }\end{array}$ & $\begin{array}{l}\text { Construction } \\
\text { sector (NAICS } \\
23 \text { ) }\end{array}$ & $\begin{array}{l}\text { Professional, } \\
\text { scientific, } \\
\text { technical } \\
\text { service sector } \\
\text { (NAICS 54) }\end{array}$ & $\begin{array}{c}\text { Waste } \\
\text { management } \\
\text { service sector } \\
\text { (NAICS 56) }\end{array}$ \\
\hline Green ARRA per capita (log) x D2005_2007 & $\begin{array}{l}-0.00149 \\
(0.00449)\end{array}$ & $\begin{array}{c}0.00367 \\
(0.00244)\end{array}$ & $\begin{array}{c}-0.000480 \\
(0.00331)\end{array}$ & $\begin{array}{c}0.00982 \\
(0.00899)\end{array}$ & $\begin{array}{l}-0.00914 \\
(0.0111)\end{array}$ \\
\hline Green ARRA per capita (log) x D2009_2012 & $\begin{array}{c}0.00182 \\
(0.00442)\end{array}$ & $\begin{array}{c}0.00148 \\
(0.00198)\end{array}$ & $\begin{array}{l}-0.000799 \\
(0.00367)\end{array}$ & $\begin{array}{l}-0.00276 \\
(0.00541)\end{array}$ & $\begin{array}{c}0.0143^{*} \\
(0.00725)\end{array}$ \\
\hline Green ARRA per capita (log) x D2013_2017 & $\begin{array}{l}0.0113 * * \\
(0.00559)\end{array}$ & $\begin{array}{c}0.00736^{* *} \\
(0.00324)\end{array}$ & $\begin{array}{c}0.0105^{*} \\
(0.00603)\end{array}$ & $\begin{array}{l}-0.0106 \\
(0.0116)\end{array}$ & $\begin{array}{c}0.0119 \\
(0.00934)\end{array}$ \\
\hline \multicolumn{6}{|l|}{ Comparison across periods: } \\
\hline Green ARRA per capita (log): 2009-2012 vs 2005-2007 & $\begin{array}{c}0.00332 \\
(0.00826)\end{array}$ & $\begin{array}{l}-0.00219 \\
(0.00261)\end{array}$ & $\begin{array}{l}-0.00032 \\
(0.00556)\end{array}$ & $\begin{array}{l}-0.01259 \\
(0.0123)\end{array}$ & $\begin{array}{c}0.02343 * * \\
(0.00980)\end{array}$ \\
\hline Green ARRA per capita (log): 2013-2017 vs 2005-2007 & $\begin{array}{c}0.01278 \\
(0.00898)\end{array}$ & $\begin{array}{c}0.00369 \\
(0.00472)\end{array}$ & $\begin{array}{l}0.01098^{*} \\
(0.00648)\end{array}$ & $\begin{array}{l}-0.0204 \\
(0.0124)\end{array}$ & $\begin{array}{c}0.02104 * * \\
(0.0103)\end{array}$ \\
\hline $\mathrm{N}$ of jobs created by $\$ 1 \mathrm{mln}$ green ARRA: short term (2009-2012) & $\begin{array}{c}0.64 \\
(1.606)\end{array}$ & $\begin{array}{c}-0.91 \\
(1.090)\end{array}$ & $\begin{array}{l}-0.06 \\
(1.060)\end{array}$ & $\begin{array}{c}-2.8 \\
(2.735)\end{array}$ & $\begin{array}{l}5.55^{* *} \\
(2.319)\end{array}$ \\
\hline $\mathrm{N}$ of jobs created by $\$ 1 \mathrm{mln}$ green ARRA: long term (2013-2017) & $\begin{array}{c}2.86 \\
(2.008)\end{array}$ & $\begin{array}{c}1.6 \\
(2.051)\end{array}$ & $\begin{array}{l}2.36^{*} \\
(1.394)\end{array}$ & $\begin{array}{c}-5.02 \\
(3.044)\end{array}$ & $\begin{array}{l}5.7 * * \\
(2.787)\end{array}$ \\
\hline R squared & 0.337 & 0.502 & 0.655 & 0.0949 & 0.188 \\
\hline Observations & 7631 & 7631 & 7631 & 7631 & 7631 \\
\hline
\end{tabular}


Table 6 - Results by occupational group

\begin{tabular}{|c|c|c|c|c|}
\hline $\begin{array}{l}\text { Dep var: Change in log employment (by occupational group) per capita } \\
\text { compared to } 2008\end{array}$ & $\begin{array}{c}\text { Abstract } \\
\text { occupations }\end{array}$ & $\begin{array}{c}\text { Manual } \\
\text { occupations }\end{array}$ & $\begin{array}{c}\text { Service } \\
\text { occupations }\end{array}$ & $\begin{array}{c}\text { Clerical } \\
\text { occupations }\end{array}$ \\
\hline Green ARRA per capita (log) x D2005_2007 & $\begin{array}{l}0.00203 \\
(0.00175)\end{array}$ & $\begin{array}{l}-0.00113 \\
(0.00277)\end{array}$ & $\begin{array}{c}0.00320 \\
(0.00250)\end{array}$ & $\begin{array}{r}0.00446^{* *} \\
(0.00209)\end{array}$ \\
\hline Green ARRA per capita (log) x D2009_2012 & $\begin{array}{l}0.00172 \\
(0.00206)\end{array}$ & $\begin{array}{l}0.00485^{*} \\
(0.00273)\end{array}$ & $\begin{array}{l}-0.00299 \\
(0.00375)\end{array}$ & $\begin{array}{r}-0.000659 \\
(0.00261)\end{array}$ \\
\hline Green ARRA per capita (log) x D2013_2017 & $\begin{array}{l}0.000885 \\
(0.00418)\end{array}$ & $\begin{array}{l}0.0119^{* *} \\
(0.00541)\end{array}$ & $\begin{array}{l}-0.00113 \\
(0.00468)\end{array}$ & $\begin{array}{c}0.00321 \\
(0.00268)\end{array}$ \\
\hline \multicolumn{5}{|l|}{ Comparison across periods: } \\
\hline Green ARRA per capita (log): 2009-2012 vs 2005-2007 & $\begin{array}{l}-0.00031 \\
(0.00348)\end{array}$ & $\begin{array}{c}0.00598 \\
(0.00414)\end{array}$ & $\begin{array}{l}-0.00619 \\
(0.00570)\end{array}$ & $\begin{array}{l}-0.00512 \\
(0.00432)\end{array}$ \\
\hline Green ARRA per capita (log): 2013-2017 vs 2005-2007 & $\begin{array}{l}-0.00114 \\
(0.00484)\end{array}$ & $\begin{array}{c}0.01299 * * \\
(0.00607)\end{array}$ & $\begin{array}{l}-0.00433 \\
(0.00629)\end{array}$ & $\begin{array}{l}-0.00124 \\
(0.00406)\end{array}$ \\
\hline $\mathrm{N}$ of jobs created by $\$ 1$ mln green ARRA: short term (2009-2012) & $\begin{array}{l}-0.47 \\
(5.285)\end{array}$ & $\begin{array}{c}5.8 \\
(4.012)\end{array}$ & $\begin{array}{c}-4.74 \\
(4.369)\end{array}$ & $\begin{array}{c}-5.38 \\
(4.542)\end{array}$ \\
\hline $\mathrm{N}$ of jobs created by $\$ 1 \mathrm{mln}$ green ARRA: long term (2013-2017) & $\begin{array}{c}-1.91 \\
(8.098)\end{array}$ & $\begin{array}{c}13.74 * * \\
(6.417)\end{array}$ & $\begin{array}{c}-3.56 \\
(5.167)\end{array}$ & $\begin{array}{c}-1.31 \\
(4.292)\end{array}$ \\
\hline R squared & 0.517 & 0.489 & 0.422 & 0.347 \\
\hline Observations & 7631 & 7631 & 7631 & 7631 \\
\hline
\end{tabular}

Notes: OLS model weighted by CZ population in 2008. Sample: $587 \mathrm{CZ}$ with at least 25,000 residents in 2008. Year fixed effects and US-Division $\mathrm{x}$ period fixed effects included. Additional control variables (interacted with D2002_2007, D2009_2012 and D2013_2017 dummies) same as Table 3. Standard errors clustered by state in parentheses. $* \mathrm{p}<0.1, * * \mathrm{p}<0.05, * * * \mathrm{p}<0.01$.

Table 7 - Focus on manual occupations

\begin{tabular}{|c|c|c|c|c|c|}
\hline $\begin{array}{l}\text { Dep var: Change in log employment (by category) per capita } \\
\text { compared to } 2008\end{array}$ & $\begin{array}{c}\text { Average } \\
\text { hourly wage } \\
\text { of manual } \\
\text { workers }\end{array}$ & $\begin{array}{c}\text { Manual } \\
\text { workers with } \\
\text { hourly wage }> \\
\text { US median } \\
\text { for manual } \\
\text { workers } \\
\end{array}$ & $\begin{array}{c}\text { Manual } \\
\text { workers with } \\
\text { hourly wage }< \\
\text { US median } \\
\text { for manual } \\
\text { workers }\end{array}$ & $\begin{array}{c}\text { Manual } \\
\text { workers with } \\
\text { education > } \\
\text { high school } \\
\text { degree }\end{array}$ & $\begin{array}{c}\text { Manual } \\
\text { workers with } \\
\text { high school } \\
\text { degree or less }\end{array}$ \\
\hline Green ARRA per capita (log) x D2005_2007 & $\begin{array}{c}0.00327 \\
(0.00474)\end{array}$ & $\begin{array}{c}-0.000777 \\
(0.00397)\end{array}$ & $\begin{array}{l}-0.00280 \\
(0.00346)\end{array}$ & $\begin{array}{c}-0.00908 \\
(0.00585)\end{array}$ & $\begin{array}{c}0.00244 \\
(0.00281)\end{array}$ \\
\hline Green ARRA per capita (log) x D2009_2012 & $\begin{array}{l}-0.00159 \\
(0.00500)\end{array}$ & $\begin{array}{c}0.00440 \\
(0.00330)\end{array}$ & $\begin{array}{c}0.00746^{* *} \\
(0.00354)\end{array}$ & $\begin{array}{l}0.0106 * * \\
(0.00509)\end{array}$ & $\begin{array}{c}0.00284 \\
(0.00329)\end{array}$ \\
\hline Green ARRA per capita (log) x D2013_2017 & $\begin{array}{c}0.00161 \\
(0.00633) \\
\end{array}$ & $\begin{array}{c}0.00930 \\
(0.00674)\end{array}$ & $\begin{array}{l}0.0164 * * * \\
(0.00568)\end{array}$ & $\begin{array}{l}0.0144 * * \\
(0.00562)\end{array}$ & $\begin{array}{c}0.0103 \\
(0.00641) \\
\end{array}$ \\
\hline \multicolumn{6}{|l|}{ Comparison across periods: } \\
\hline Green ARRA per capita (log): 2009-2012 vs 2005-2007 & $\begin{array}{l}-0.00485 \\
(0.00935)\end{array}$ & $\begin{array}{c}0.00517 \\
(0.00620)\end{array}$ & $\begin{array}{l}0.01026^{*} \\
(0.00564)\end{array}$ & $\begin{array}{c}0.01966 * * \\
(0.00877)\end{array}$ & $\begin{array}{c}0.0004 \\
(0.00519)\end{array}$ \\
\hline Green ARRA per capita (log): 2013-2017 vs 2005-2007 & $\begin{array}{c}-0.00166 \\
(0.0103)\end{array}$ & $\begin{array}{c}0.01007 \\
(0.00815)\end{array}$ & $\begin{array}{c}0.01923 * * \\
(0.00750)\end{array}$ & $\begin{array}{c}0.02346 * * \\
(0.00931)\end{array}$ & $\begin{array}{c}0.00787 \\
(0.00752)\end{array}$ \\
\hline $\mathrm{N}$ of jobs created by $\$ 1 \mathrm{mln}$ green ARRA: short term (2009-2012) & $\begin{array}{c}-0.0028 \\
(0.00547)\end{array}$ & $\begin{array}{c}2.67 \\
(3.196)\end{array}$ & $\begin{array}{c}4.68^{*} \\
(2.573)\end{array}$ & $\begin{array}{l}5.46^{* *} \\
(2.436)\end{array}$ & $\begin{array}{c}0.28 \\
(3.600)\end{array}$ \\
\hline $\mathrm{N}$ of jobs created by $\$ 1$ mln green ARRA: long term (2013-2017) & $\begin{array}{c}-0.0011 \\
(0.00660) \\
\end{array}$ & $\begin{array}{c}5.74 \\
(4.644) \\
\end{array}$ & $\begin{array}{l}9.45^{* *} \\
(3.687) \\
\end{array}$ & $\begin{array}{l}7.44 * * \\
(2.954) \\
\end{array}$ & $\begin{array}{c}5.85 \\
(5.594) \\
\end{array}$ \\
\hline R squared & 0.304 & 0.392 & 0.381 & 0.273 & 0.474 \\
\hline $\mathrm{N}$ of $\mathrm{CZ}$ & 587 & 587 & 587 & 587 & 587 \\
\hline Observations & 7631 & 7631 & 7631 & 7631 & 7631 \\
\hline
\end{tabular}

Notes: OLS model weighted by CZ population in 2008. Sample: CZ with at least 25,000 residents in 2008. Year fixed effects and US-Division x period fixed effects included. Additional control variables (interacted with D2002_2007, D2009_2012 and D2013_2017 dummies) same as Table 3. Standard errors clustered by state in parentheses. ${ }^{*} \mathrm{p}<0.1,{ }^{*} \mathrm{p}<0.05,{ }^{* * *} \mathrm{p}<0.01$. 


\section{Distributional Effects of Green Stimulus}

Our results for different sectors of the economy suggest that the green stimulus might have important distributional effects. In this section, we consider whether the effect of green stimulus varies for different types of workers. We estimate separate models for different broad groups of workers following a standard grouping in the literature on task-biased technological change (Acemoglu and Autor, 2011): abstract occupations, service workers, clerical occupations, and manual labor (see Table A5 in Appendix A4).

Table 6 shows results for these four occupational groups. The important result here is that nearly all job creation from green ARRA occurs in manual labor occupations. Recall from column (1) of Table 3 that $\$ 1$ million green ARRA created 14.76 total jobs in the long-term. Nearly all of those (13.74) are manual labor jobs. Interestingly, the pre-trends associated with green ARRA allocation also appear insignificant (and are negative) when focusing solely on manual labor. Given the importance of manual labor in the debate on the distributional effects of trade and technology shocks (e.g., Autor et al., 2013; Acemoglu and Restrepo, 2020), we provide an in-depth look at how the green stimulus affected manual labor. Table 7 considers the effect of green ARRA on manual labor wages (columns 1-3) and on educational attainment of manual workers. First, column 1 replaces changes in per capita employment as the dependent variable with the average hourly wage of manual workers. Despite increasing demand for manual labor, green ARRA investments did not increase the wages of manual workers. In columns (2) and (3), we see that most of the increase in manual labor jobs occurred in jobs where workers earned less than the US median wage for all manual workers. This missing wage gains highlight the well-known deterioration of the bargaining power of manual workers that requires other solutions than public spending in the green economy. While the manual labor jobs created by green ARRA were not 
high-paying jobs, they are not necessarily low skilled jobs. In the last two columns, we see that most of the increase in manual labor work is among manual workers who have more than a highschool education. In fact, this is the one group of workers where green ARRA investments created jobs in both the short term (5.46 jobs per $\$ 1$ million) and long term (7.44 jobs per $\$ 1$ million). While the green stimulus increased demand for manual labor workers, these jobs still required higher education and were not better paying than existing jobs.

\section{E. Robustness Checks}

Finally, we present a series of robustness checks that address some critical aspects of our identification strategy (Table 8). Each of these robustness checks uses our preferred specification using census division fixed effects. In column (1) we exclude commuting zones in the highest and lowest vigintiles of non-green ARRA spending, as the standard deviation in per capita non-green ARRA is much higher for these two groups. In column (2), we drop commuting zones from other potentially problematic vigintiles. Recall that the standard deviation of green ARRA within each vigintile is very similar, with the exception of the first two vigintiles of non-green ARRA spending and a vigintile in the middle (the $14^{\text {th }}$ vigintile). We drop those three vigintiles here. Columns (3) and (4) exclude commuting zones with unbalanced characteristics of some key covariates: those CZ hosting federal R\&D laboratories (column 3) and those with a high level of shale gas activity (column 4). Finally, our main models exclude commuting zones with less than 25,000 residents in 2008. In column (5) we include those communing zones. Our results are generally robust. The number of jobs created remains between 11.6 and 21.81 per $\$ 1$ million green ARRA. The longrun effect of the stimulus is highest when excluding commuting zones with high levels of shale gas activity, and lowest when excluding commuting zones with federal R\&D laboratories. The

additionality effect $\left(\hat{\beta}_{\text {long }}-\hat{\beta}_{\text {pre }}\right)$ is insignificant when excluding federal laboratories, although 
the direct long-run effect is statistically significant. Pre-trends are insignificant in this specification, and are about 20 percent smaller than in our main model.

Table 8 - Robustness checks: various

\begin{tabular}{|c|c|c|c|c|c|}
\hline Dep var: Change in log employment per capita compared to 2008 & $\begin{array}{l}\text { (1) } \\
\text { Excluding 1st } \\
\text { and 20th } \\
\text { vigintiles }\end{array}$ & $\begin{array}{c}(2) \\
\text { Excluding } \\
\text { other } \\
\text { problematic } \\
\text { vigintiles: 1st, } \\
\text { 2nd, 14th } \\
\end{array}$ & $\begin{array}{c}(3) \\
\text { Excluding CZs } \\
\text { hosting } \\
\text { Federal R\&D } \\
\text { Labs }\end{array}$ & $\begin{array}{c}(4) \\
\text { Excluding CZs } \\
\text { with shale gas } \\
\text { extraction } \\
\text { activities }\end{array}$ & $\begin{array}{l}\text { Including CZs } \\
\text { with less than } \\
25 \mathrm{k} \text { residents }\end{array}$ \\
\hline Green ARRA per capita (log) x D2005_2007 & $\begin{array}{c}0.00146 \\
(0.00123)\end{array}$ & $\begin{array}{c}0.00111 \\
(0.00113)\end{array}$ & $\begin{array}{c}0.00163 \\
(0.00118)\end{array}$ & $\begin{array}{c}0.00175^{*} \\
(0.000914)\end{array}$ & $\begin{array}{c}0.00188^{*} \\
(0.000986)\end{array}$ \\
\hline Green ARRA per capita (log) x D2005_2007 & $\begin{array}{l}0.00181^{*} \\
(0.00108)\end{array}$ & $\begin{array}{c}0.00102 \\
(0.00101)\end{array}$ & $\begin{array}{c}0.00157 \\
(0.000971)\end{array}$ & $\begin{array}{l}0.00190 * * \\
(0.000876)\end{array}$ & $\begin{array}{l}0.00189 * * \\
(0.000809)\end{array}$ \\
\hline Green ARRA per capita (log) x D2005_2007 & $\begin{array}{c}0.00526 * * \\
(0.00222)\end{array}$ & $\begin{array}{c}0.00506^{* *} \\
(0.00214)\end{array}$ & $\begin{array}{l}0.00413^{* *} \\
(0.00204)\end{array}$ & $\begin{array}{c}0.00645^{* * *} * \\
(0.00205)\end{array}$ & $\begin{array}{c}0.00448 * * * \\
(0.00152)\end{array}$ \\
\hline \multicolumn{6}{|l|}{ Comparison across periods: } \\
\hline Green ARRA per capita (log): 2009-2012 vs 2005-2007 & $\begin{array}{c}0.00036 \\
(0.00135)\end{array}$ & $\begin{array}{l}-0.00008 \\
(0.00131)\end{array}$ & $\begin{array}{l}-0.00007 \\
(0.00104)\end{array}$ & $\begin{array}{c}0.00015 \\
(0.00112)\end{array}$ & $\begin{array}{c}0.000002 \\
(0.000910)\end{array}$ \\
\hline Green ARRA per capita (log): 2013-2017 vs 2005-2007 & $\begin{array}{l}0.00381^{*} \\
(0.00222)\end{array}$ & $\begin{array}{l}0.00396^{*} \\
(0.00215) \\
\end{array}$ & $\begin{array}{c}0.0025 \\
(0.00189) \\
\end{array}$ & $\begin{array}{l}0.0047 * * \\
(0.00224) \\
\end{array}$ & $\begin{array}{c}0.0026^{*} \\
(0.00154) \\
\end{array}$ \\
\hline $\mathrm{N}$ of jobs created by $\$ 1 \mathrm{mln}$ green ARRA: short term (2009-2012) & 1.55 & -0.36 & -0.29 & 0.64 & 0.01 \\
\hline s.e. & $(5.863)$ & $(5.666)$ & $(4.518)$ & $(4.863)$ & $(3.946)$ \\
\hline $\mathrm{N}$ of jobs created by $\$ 1$ mln green ARRA: long term (2013-2017) & $17.67^{*}$ & $18.37^{*}$ & 11.6 & $21.81 * *$ & $12.04^{*}$ \\
\hline s.e. & $(10.30)$ & $(9.961)$ & $(8.768)$ & $(10.42)$ & $(7.133)$ \\
\hline R squared & 0.681 & 0.698 & 0.634 & 0.753 & 0.650 \\
\hline $\mathrm{N}$ of $\mathrm{CZ}$ & 559 & 507 & 563 & 385 & 689 \\
\hline Observations & 7267 & 6591 & 7319 & 5005 & 8957 \\
\hline
\end{tabular}

\section{Discussion}

We perform a comprehensive evaluation of the economic effect of green stimulus using the historical experience of the American Recovery Act, which represents the largest push to the green economy to date. Our results inform both current policy debates and address longer-term concerns about job losses in the transition to a green economy. Currently, some environmentalists advocate green new deal programs as a win-win solution to both relaunch sluggish economic growth in developed countries and to tackle climate change. The Covid-19 lockdown has led to calls for large-scale investments in the green economy. While the size of the green stimulus of 
2009 is small compared to what is at stake for a post-Covid-19 recovery, our research highlights interesting features of a green stimulus that can offer guidance to the design of future green stimulus programs.

First, our results suggest green ARRA works more slowly than other stimulus investments. The long-run effect of green ARRA on total employment is in the mid-range of previous estimates, with just under 15 jobs created per $\$ 1$ million of green ARRA. The persistency of the job creation effect is clearly a positive aspect of the green fiscal stimulus. However, the timing of green ARRRA's impact differs from previous studies of other ARRA investments, which generally find short-term effects. For green ARRA, we find little evidence of short-run employment gains. Green stimulus investments reinforce long-run growth, but alone are not sufficient for a short-term stimulus. The timing of green stimulus investments has two implications. First, green stimulus investments appear more effective for reshaping an economy than for restarting an economy. While our focus is on the potential employment benefits from green investments, future research should also consider the potential environmental benefits of green stimulus, as the long-run impacts on employment suggest that green investments lead to durable changes in the green economy. Second, while beyond the scope of this analysis, it may be that green stimulus investments need to be combined with other standard short-term responses, such as extensions to unemployment benefits and financial support to business, to provide immediate impact.

Second, the impact of the green stimulus becomes much clearer when we explore several dimensions of heterogeneity. The pre-existing level of green skills matters. Green ARRA creates more jobs in commuting zones with larger initial shares of occupations that use intensively such skills. The bottom line is that the green stimulus has been particularly effective in picking winners - e.g. enhancing opportunities in communities already in position to support a green economy. 
Care must be taken to match green investments to the skill base of the local economy. To support communities without the required green skills, expanding specific technical programs and engineering education (the most important green skills) could complement green stimulus investments. Evaluation of such training programs is left for future work.

Third, a green stimulus has potential to reshape an economy and thus may have important distributional effects. Because nearly half of the jobs created by green ARRA investments were in construction or waste management, green ARRA increases the demand for manual laborers. Importantly, pre-trends are not an issue when we study how the effect of green ARRA varies across sectors and occupations. Beyond the direct impacts of a green stimulus, these results also have broader implications for whether governments can help ease labor market transitions in response to environmental policy. Recent studies suggest that environmental regulation may reduce jobs in specific sectors, particularly for lower skilled manual labor (Marin and Vona, 2019; Yip, 2019). In contrast, subsidies to green infrastructure can benefit unskilled workers and thus may enhance the political support for other climate policies. However, wage gains did not follow the increase in the demand of manual tasks in areas receiving higher green subsidies. Exploring whether this is due to the fact that green jobs in construction are of low quality compared to similar jobs, or to the widespread deterioration of employment opportunities of the unskilled requires the use of longitudinal worker-level data and is left for future research.

\section{References}

Acemoglu, D. and Autor, D. 2011. Skills, Tasks and Technologies: Implications for Employment and Earnings. Handbook of Labor Economics Volume 4, Orley Ashenfelter and David E. Card (eds.), Amsterdam: Elsevier

Acemoglu, D. and Restrepo, P., 2020. Robots and jobs: Evidence from US labor markets. Journal of Political Economy forthcoming. 
Aldy, J.E. 2013. Policy Monitor-A preliminary assessment of the American Recovery and Reinvestment Act's Clean Energy Package. Review of Environmental Economics and Policy, 7(1): 136-155.

Altonji, J.G., Elder, T.E. and Taber, C.R., 2005. Selection on observed and unobserved variables: Assessing the effectiveness of Catholic schools. Journal of political economy, 113(1), pp.151-184.

American Recovery and Reinvestment Act of 2009, Pub. L. 111-5, 123 Stat. 115, Section 3.

Angrist, J.D. and Pischke, J.S., 2008. Mostly harmless econometrics: An empiricist's companion. Princeton university press.

Auerbach, A.J., Gorodnichenko, Y. and Murphy, D., 2019. Local fiscal multipliers and fiscal spillovers in the United States (No. w25457). National Bureau of Economic Research.

Autor, D., Levy, F., and Murnane, R. (2003), The skill content of recent technological change: An empirical exploration. Quarterly Journal of Economics 118 (4), 1279-1333.

Autor, D., Dorn, D. and Hanson, G.H., 2013. The China syndrome: Local labor market effects of import competition in the United States. American Economic Review, 103(6), pp.2121-68.

Chodorow-Reich, G., Feiveson, L., Liscow, Z. and Woolston, W.G., 2012. Does state fiscal relief during recessions increase employment? Evidence from the American Recovery and Reinvestment Act. American Economic Journal: Economic Policy, 4(3), pp.118-45.

Chodorow-Reich, G., 2019. Geographic cross-sectional fiscal spending multipliers: What have we learned?. American Economic Journal: Economic Policy, 11(2), pp.1-34.

Conley, T.G. and Dupor, B., 2013. The American Recovery and Reinvestment Act: Solely a Government Jobs Program?. Journal of monetary Economics, 60(5), pp.535-549.

Curtis, E.M., 2018. Who loses under cap-and-trade programs? the labor market effects of the nox budget trading program. Review of Economics and Statistics, 100(1), pp.151-166.

Council of Economic Advisers, 2013. The Economic Impact of the American Recovery and Reinvestment Act of 2009, Ninth Quarterly Report.

Council of Economic Advisers, 2014. The Economic Impact of the American Recovery and Reinvestment Act Five Years Later. Chapter 3 in Economic Report of the President. United States Government Printing Office, Washington, DC.

Department of Energy, 2010. Recovery Act State Memos: Massachusetts. Available at: https://www.energy.gov/downloads/massachusetts-recovery-act-state-memo

Dierdorff, E., Norton, J., Drewes, D., Kroustalis, C., Rivkin, D., and Lewis, P. (2009), Greening of the World of Work: Implications for O*NET-SOC and New and Emerging Occupations. National Center for O*NET Development.

Dupor, B. and Mehkari, M.S., 2016. The 2009 Recovery Act: Stimulus at the extensive and intensive labor margins. European Economic Review, 85, pp.208-228.

Dupor, B. and McCrory, P.B., 2018. A Cup Runneth Over: Fiscal Policy Spillovers from the 2009 Recovery Act. The Economic Journal, 128(611), pp.1476-1508. 
Environmental Protection Agency, 2009. American Recovery and Reinvestment Act Funding for the National Clean Diesel Funding Assistance Program (February 2009).

Ferris, A.E., Shadbegian, R.J. and Wolverton, A., 2014. The effect of environmental regulation on power sector employment: Phase I of the title IV SO2 trading program. Journal of the Association of Environmental and Resource Economists, 1(4), pp.521-553.

Fowlie, M., Greenstone, M. and Wolfram, C., 2018. Do energy efficiency investments deliver? Evidence from the weatherization assistance program. The Quarterly Journal of Economics, 133(3), pp.1597-1644.

Garin, A., 2019. Putting America to work, where? Evidence on the effectiveness of infrastructure construction as a locally targeted employment policy. Journal of Urban Economics, 111, pp.108-131.

Goldsmith-Pinkham, P., Sorkin, I. and Swift, H., 2018. Bartik instruments: What, when, why, and how. (No. w24408). National Bureau of Economic Research.

Greenstone, M., 2002. The Impacts of Environmental Regulations on Industrial Activity: Evidence from the 1970 and 1977 Clean Air Act Amendments and the Census of Manufactures. Journal of Political Economy, 110(6), 1175-1219.

Helm, D., 2020. The environmental impacts of the coronavirus. Environmental and Resource Economics, 76: 21-38.

Jaeger, D.A., Ruist, J. and Stuhler, J., 2018. Shift-share instruments and the impact of immigration (No. w24285). National Bureau of Economic Research.

Hafstead, M.A. and Williams III, R.C., 2018. Unemployment and environmental regulation in general equilibrium. Journal of Public Economics, 160, pp.50-65.

House Energy and Commerce Subcommittee on Oversight and Investigations Hearing: "Oversight of DOE (Energy Department) Recovery Act Spending."[3]2011, Federal Information \& News Dispatch, LLC, Washington.

Imbens, G., and Angrist, J. 1994. Identification and Estimation of Local Average Treatment Effects. Econometrica, 62(2): 467-475.

Kahn, M., and Mansur, E. (2013), Do local energy prices and regulation affect the geographic concentration of employment? Journal of Public Economics 101, 105-114.

Marin, G. and Vona, F., (2017), The impact of energy prices on employment and environmental performance: Evidence from French manufacturing establishments. OFCE Working Paper.

Marin, G. and Vona, F., 2019. 'Climate Policies and Skill-Biased Employment Dynamics: evidence from EU countries', Journal of Environmental Economics and Management 98

Martin, R., L. B. de Preux, and U. J. Wagner (2014). The impact of a carbon tax on manufacturing: Evidence from microdata. Journal of Public Economics 117 (C), 1-14.

Metcalf, G.E. and Stock, J.H., 2020, May. Measuring the Macroeconomic Impact of Carbon Taxes. AEA Papers and Proceedings, Vol. 110, pp. 101-06.

Morgenstern, R., Pizer, W. and Shih, J. (2002), Jobs versus the environment: an industry-level perspective. Journal of Environmental Economics and Management, 43(3), 412-436. 
Moretti, E. (2010), Local Multipliers, American Economic Review 100(2), 373-377.

Mundaca, L. and Richter, J.L., 2015. Assessing 'green energy economy'stimulus packages: Evidence from the US programs targeting renewable energy. Renewable and Sustainable Energy Reviews, 42, pp.1174-1186.

Nakamura, E. and Steinsson, J., 2014. Fiscal stimulus in a monetary union: Evidence from US regions. American Economic Review, 104(3), pp.753-92.

Office of the Vice President, 2010. 100 Recovery Act Projects that are Changing America.

Ruggles, S., Flood, S., Goeken, R., Grover, J., Meyer, E., Pacas, J. and Sobek, M., 2020. IPUMS USA: Version $10.0 \quad$ [dataset]. Minneapolis, $\mathrm{MN}$ : IPUMS. https://doi.org/10.18128/D010.V10.0

Vona, F., Marin, G., Consoli, D., Popp, D., 2018. 'Environmental Regulation and Green Skills: an empirical exploration,' Journal of the Association of Environmental and Resource Economists vol. 5(4): 713-753

Vona, F., Marin, G., Consoli, D., 2019. 'Measures, Drivers and Effects of Green Employment: evidence from US metropolitan and non-metropolitan areas, 2006-2014,' Journal of Economic Geography 19, 1021-1048.

White House, 2010. 2010 Fiscal Year Report to the President on Progress of Implementing the American Recovery and Reinvestment Act of 2009.

Yamazaki, A. 2017. Jobs and climate policy: Evidence from British Columbia's revenue-neutral carbon tax. Journal of Environmental Economics and Management, 83: 197-216.

Yip, C.M. 2018. On the labor market consequences of environmental taxes. Journal of Environmental Economics and Management 89, 136-152.

Walker, R.W. 2011. Environmental regulation and labor reallocation: Evidence from the Clean Air Act. American Economic Review 101(3), 442-447.

Wilson, D.J., 2012. Fiscal spending jobs multipliers: Evidence from the 2009 American Recovery and Reinvestment Act. American Economic Journal: Economic Policy, 4(3), pp.251-82. 


\section{Appendix A - Data Appendix}

\section{A1 - Background on Green ARRA investments}

Table A1 - Descriptive statistics for green and non-green ARRA

\begin{tabular}{|c|c|c|c|c|c|c|}
\hline & $\begin{array}{c}\text { Non-green } \\
\text { ARRA }\end{array}$ & Green ARRA & DOE ARRA & EPA ARRA & $\begin{array}{c}\text { Green research } \\
\text { ARRA }\end{array}$ & $\begin{array}{c}\text { Green training } \\
\text { ARRA }\end{array}$ \\
\hline Total, million \$ & 262,530 & 61,175 & 52,119 & 9,056 & 6,191 & 228 \\
\hline \multicolumn{7}{|c|}{ By commuting zone, million $\$$} \\
\hline mean & 441.62 & 103.36 & 88.13 & 15.22 & 10.55 & 0.39 \\
\hline s.d. & 988.06 & 308.53 & 294.20 & 28.97 & 70.20 & 1.38 \\
\hline $\min$ & 1.59 & 0.00 & 0.00 & 0.00 & 0.00 & 0.00 \\
\hline median & 142.54 & 18.27 & 10.19 & 6.07 & 0.00 & 0.00 \\
\hline $\max$ & $9,963.45$ & $3,677.57$ & $3,601.58$ & 297.57 & $1,163.62$ & 11.96 \\
\hline \multicolumn{7}{|c|}{ by commuting zone, per capita } \\
\hline mean & 988.47 & 260.33 & 213.00 & 47.33 & 23.70 & 0.67 \\
\hline s.d. & 630.78 & $1,303.29$ & $1,298.28$ & 65.82 & 313.19 & 3.83 \\
\hline $\min$ & 8.65 & 0.00 & 0.00 & 0.00 & 0.00 & 0.00 \\
\hline median & 821.48 & 104.67 & 57.81 & 27.40 & 0.00 & 0.00 \\
\hline $\max$ & $6,799.15$ & $28,398.38$ & $28,292.04$ & 640.88 & $7,377.34$ & 70.33 \\
\hline
\end{tabular}

Notes: data by 587 commuting zone includes only CZ with at least 25000 inhabitants. ARRA for years 2009-2012 divided by population in 2008 (dollars per capita).

Table A2 - Top 10 areas in terms of green and non-green ARRA per capita

\begin{tabular}{lccc}
\hline & Top 10 CZ by green ARRA per capita & \\
Mreen ARRA per & Non-green & Population in \\
Main county of the CZ & capita & 1163 & 2008 \\
\hline Morgan County, IL & 28398 & 1035 & 55090 \\
Orangeburg County, SC & 8283 & 599 & 157729 \\
Benton County, WA & 6754 & 1098 & 298566 \\
Elko County, NV & 5722 & 1711 & 59144 \\
Alamosa County, CO & 4130 & 1089 & 45845 \\
Lee County, MS & 3031 & 1054 & 204392 \\
Frederick County, MD & 2856 & 712 & 709225 \\
Santa Barbara County, CA & 2313 & 922 & 682217 \\
Knox County, TN & 2294 & 1478 & 29165 \\
Larimer County, CO & 1839 & & \\
\hline & Non-green & Green ARRA per & Population in \\
Main county of the CZ & ARRA per capita & capita & 2008 \\
\hline Sangamon County, IL & 6799 & 291 & 321216 \\
Fairbanks North Star Borough, AK & 4900 & 185 & 101940 \\
Clarke County, IA & 3978 & 330 & 33184 \\
Leon County, FL & 3925 & 456 & 383912 \\
Union County, IA & 3666 & 136 & 28110 \\
Stutsman County, ND & 3565 & 760 & 34258 \\
Bell County, TX & 3509 & 59 & 398202 \\
Montgomery County, KY & 3184 & 127 & 116545 \\
Morgan County, GA & 3171 & 125 & 34433 \\
Thurston County, WA & 3069 & 154 & 379016 \\
\hline Notes: only CZ with at least 25000 inhabitants. ARRA for years $2009-2012$ divided by population in \\
2008 (dollars per capita). Main county of the CZ identified as the county with the largest population level.
\end{tabular}


Figure A1 - Green ARRA spending per capita by Commuting Zone

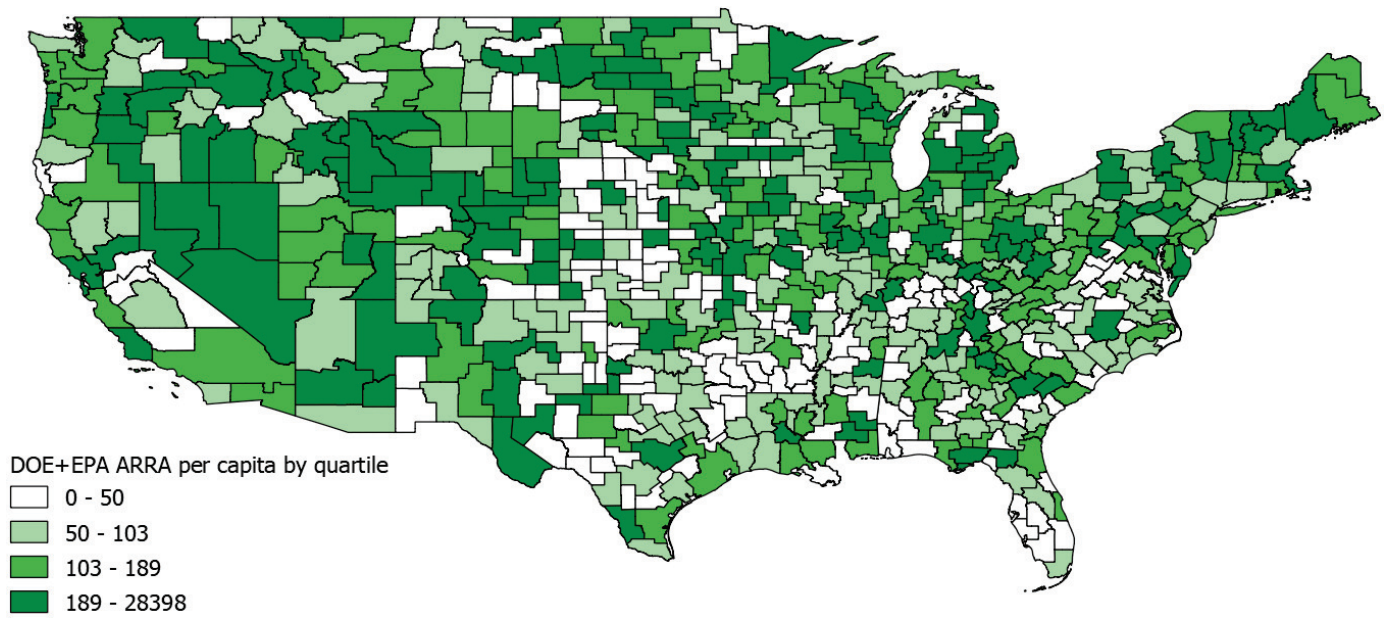

Notes: own elaboration based on Recovery.gov data from NBER data repository. Green ARRA is defined as ARRA spending awarded by DOE and EPA broken down by quartiles. Per capita analysis based on the population of each commuting zone prior to the recession, in 2008. Alaska and Hawaii not shown.

Figure A2 - Non-green ARRA spending per capita by Commuting Zone

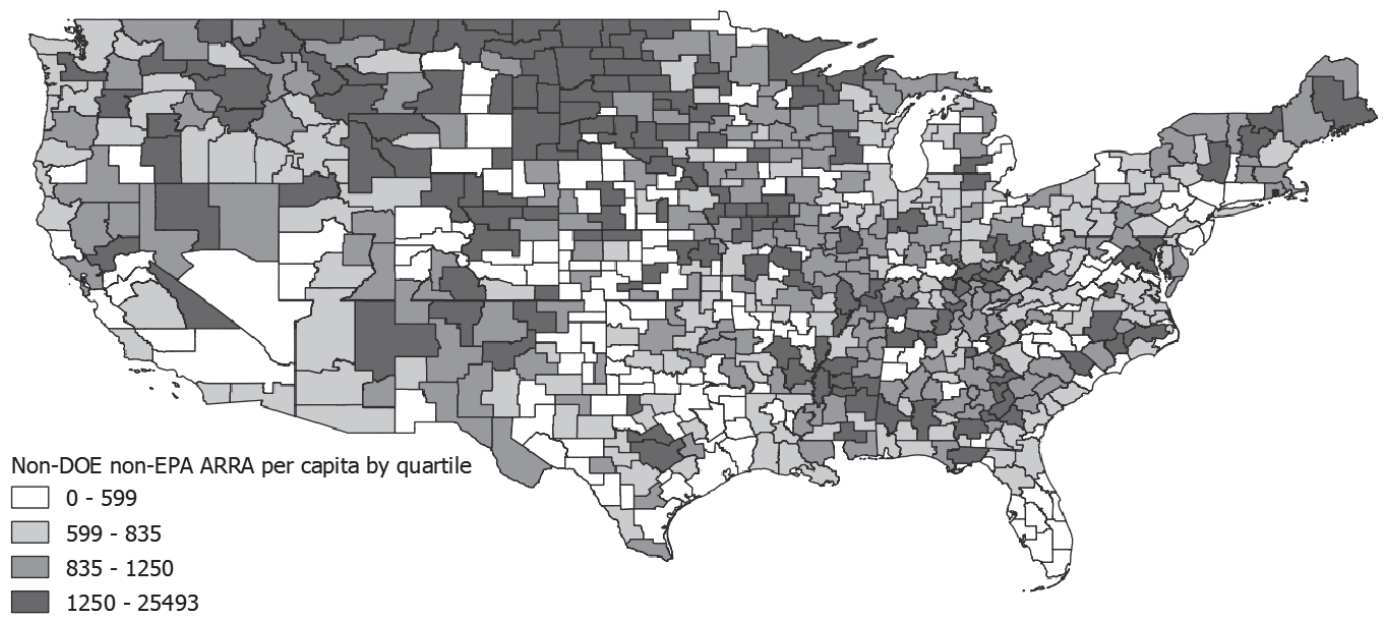

Notes: own elaboration based on Recovery.gov data from NBER data repository. Non-green ARRA is defined as ARRA spending awarded by all agencies except DOE and EPA broken down by quartiles. Per capita analysis based on the population of each commuting zone prior to the recession, in 2008. Alaska and Hawaii not shown. 
Figure A3 - Share of green ARRA in total ARRA spending by Commuting Zone

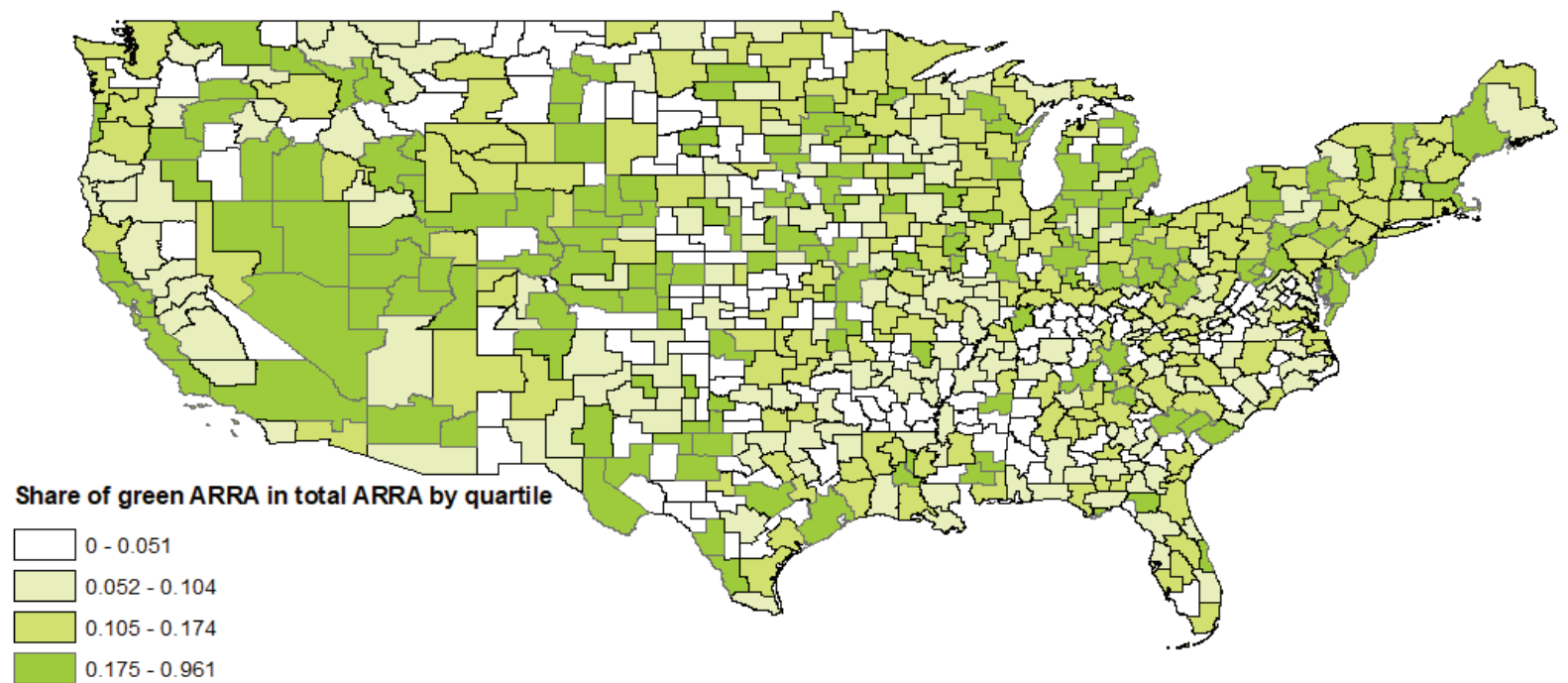

Notes: own calculation based on Recovery.gov data from NBER data repository. Green ARRA is defined as ARRA spending awarded by the DOE and EPA. Each shade represents a different quartile. Alaska and Hawaii not shown. 


\section{A2 - Control variables: definitions and data sources}

Data on average annual employment level by county and year is retrieved from the BLSQCEW (Quarterly Census of Employment and Wages of the Bureau of Labor Statistics). Countylevel data are then aggregated up at the CZ level. We use BLS-QCEW also to estimate employment by industry. In all regressions, we account for the base-year (2008) level of CZ employment per capita by industry as well as the growth in CZ employment per capita (population in 2008) by industry and total over the period 2000-2007 (pre-trends).

Data on unemployed persons is obtained from the BLS-LAUS Local Unemployment Statistics database while data on county-level population and personal income per capita is retrieved from the database maintained by the Bureau of Economic Analysis.

Data on occupations and skills are based on microdata from the Decennial Census $(5 \%$ sample, year 2000) and the American Community Survey (ACS, 1\% sample of the US population, years 2005-2017) available at IPUMS (Integrated Public Use Microdata Series, Ruggles et al., 2020). We just consider working-age (16-64) employed persons. We allocate worker-level information to CZs based on the worker's place of work (county place of work: $59.2 \%$ of workers; PUMA place of work: $32.5 \%$ of workers $)$ and, when not available, county of residence $(8.3 \%$ of

workers). Based on the definition of commuting zone, most of these residual workers should be employed within the same $\mathrm{CZ}$ where they reside.

As described briefly in Section III.A of the paper, we use ACS microdata to build our indicator of GGS endowment. For all 448 SOC-based occupations, we compute for years 2000 (Decennial Census) and 2005 (ACS) the average importance score of Green General Skills (GGS, see Vona et al., 2018) using data on tasks and skills from the O*NET (Occupational Information Network) database (version: 18.0). Based on the national cross-occupation weighted (by sample 
weights times hours worked) distribution of GGS importance scores in 2000, we compute the 75th

percentile of the distribution. Then, using data from ACS for 2005, we compute the share of hours

worked by employees in each CZ in occupations above the threshold of GGS (see Table A3) over

total hours worked by employees in each $\mathrm{CZ}$.

Table A3 - List of occupations in the top quartile of GGS

\begin{tabular}{|c|c|}
\hline SOC code & Occupation title \\
\hline 111021 & General and Operations Managers \\
\hline 113051 & Industrial Production Managers \\
\hline 113061 & Purchasing Managers \\
\hline 119021 & Constructions Managers \\
\hline 119111 & Medical and Health Services Managers \\
\hline 119121 & Natural Science Managers \\
\hline 131023 & Purchasing Agents, Except Wholesale, Retail, and Farm Products \\
\hline 131051 & Cost Estimators \\
\hline 131081 & Logisticians \\
\hline 132099 & Financial Specialists, All Other \\
\hline 171010 & Architects, Except Naval \\
\hline 171020 & Surveyors, Cartographers, and Photogrammetrists \\
\hline 172011 & Aerospace Engineers \\
\hline 172041 & Chemical Engineers \\
\hline 172051 & Civil Engineers \\
\hline 172061 & Computer Hardware Engineers \\
\hline 172070 & Electrical and Electronics Engineers \\
\hline 172081 & Environmental Engineers \\
\hline 172110 & Industrial Engineers, including Health and Safety \\
\hline 172121 & Marine Engineers and Naval Architects \\
\hline 172131 & Materials Engineers \\
\hline 172141 & Mechanical Engineers \\
\hline 173010 & Drafters \\
\hline 173020 & Engineering Technicians, Except Drafters \\
\hline 173031 & Surveying and Mapping Technicians \\
\hline 191010 & Agricultural and Food Scientists \\
\hline 191020 & Biological Scientists \\
\hline 191030 & Conservation Scientists and Foresters \\
\hline 192010 & Astronomers and Physicists \\
\hline 192021 & Atmospheric and Space Scientists \\
\hline 192030 & Chemists and Materials Scientists \\
\hline 192040 & Environmental Scientists and Geoscientists \\
\hline 192099 & Physical Scientists, All Other \\
\hline 193051 & Urban and Regional Planners \\
\hline $2590 X X$ & Other Education, Training, and Library Workers \\
\hline 291011 & Chiropractors \\
\hline 291020 & Dentists \\
\hline 291031 & Dieticians and Nutritionists \\
\hline 291041 & Optometrists \\
\hline 291051 & Pharmacists \\
\hline 291060 & Physicians and Surgeons \\
\hline 291071 & Physician Assistants \\
\hline 291081 & Podiatrists \\
\hline
\end{tabular}




\begin{tabular}{|c|c|}
\hline SOC code & Occupation title \\
\hline 291123 & Physical Therapists \\
\hline 291124 & Radiation Therapists \\
\hline 291126 & Respiratory Therapists \\
\hline 291131 & Veterinarians \\
\hline 291181 & Audiologists \\
\hline 292010 & Clinical Laboratory Technologists and Technicians \\
\hline 292030 & Diagnostic Related Technologists and Technicians \\
\hline 292041 & Emergency Medical Technicians and Paramedics \\
\hline 299000 & Other Healthcare Practitioners and Technical Occupations \\
\hline 331012 & First-Line Supervisors of Police and Detectives \\
\hline 331021 & First-Line Supervisors of Fire Fighting and Prevention Workers \\
\hline 331099 & First-Line Supervisors of Protective Service Workers, All Other \\
\hline 332011 & Firefighters \\
\hline 332020 & Fire Inspectors \\
\hline 333021 & Detectives and Criminal Investigators \\
\hline 371012 & First-Line Supervisors of Landscaping, Lawn Service, \& Groundskeeping Workers \\
\hline 372021 & Pest Control Workers \\
\hline 413099 & Sales Representatives, Services, All Other \\
\hline 419031 & Sales Engineers \\
\hline 452011 & Agricultural Inspectors \\
\hline 454011 & Forest and Conservation Workers \\
\hline 471011 & First-Line Supervisors of Construction Trades and Extraction Workers \\
\hline 472011 & Boilermakers \\
\hline 472111 & Electricians \\
\hline 472150 & Pipelayers, Plumbers, Pipefitters, and Steamfitters \\
\hline 472211 & Sheet Metal Workers \\
\hline 474011 & Construction and Building Inspectors \\
\hline 474021 & Elevator Installers and Repairers \\
\hline 474041 & Hazardous Materials Removal Workers \\
\hline 474051 & Highway Maintenance Workers \\
\hline 475031 & Explosives Workers, Ordnance Handling Experts, and Blasters \\
\hline 475040 & Mining Machine Operators \\
\hline 491011 & First-Line Supervisors of Mechanics, Installers, and Repairers \\
\hline 493011 & Aircraft Mechanics and Service Technicians \\
\hline 499021 & Heating, Air Conditioning, and Refrigeration Mechanics and Installers \\
\hline 499044 & Millwrights \\
\hline $49904 X$ & Industrial and Refractory Machinery Mechanic \\
\hline 499051 & Electrical Power-Line Installers and Repairers \\
\hline 499094 & Locksmiths and Safe Repairers \\
\hline 518010 & Power Plant Operators, Distributors, and Dispatchers \\
\hline 518021 & Stationary Engineers and Boiler Operators \\
\hline 518031 & Water and Wastewater Treatment Plant and System Operators \\
\hline 518090 & Miscellaneous Plant and System Operators \\
\hline 532010 & Aircraft Pilots and Flight Engineers \\
\hline 536051 & Transportation Inspectors \\
\hline $1110 X X$ & Chief Executives and Legislators \\
\hline 119013 & Farmers, Ranchers, and Other Agricultural Managers \\
\hline 119041 & Architectural and Engineering Managers \\
\hline 119199 & Funeral Directors \\
\hline $119 X X X$ & Miscellaneous Managers, Including Funeral Service Managers and Postmasters and Mail Superintendents \\
\hline 131041 & Compliance Officers, Except Agriculture, Construction, Health and SAfety, and Transportation \\
\hline 151111 & Computer Scientists and Systems Analysts \\
\hline 151121 & Computer and Information Research Scientists \\
\hline 151122 & Information Security Analysts \\
\hline 151143 & Computer Network Architects \\
\hline $1720 X X$ & Biomedical and agricultural engineers \\
\hline $1721 X X$ & Petroleum, mining and geological engineers, including mining safety engineers \\
\hline $1721 Y Y$ & Miscellaneous engineeers including nuclear engineers \\
\hline
\end{tabular}




\begin{tabular}{|l|l|}
\hline SOC code & Occupation title \\
\hline 1910XX & Medical Scientists, and Life Scientists, All Other \\
\hline 1930XX & Miscellaneous Social Scientists, Including Survey Researchers and Sociologists \\
\hline 1940YY & Miscellaneous Life, Physical, and Social Science Technicians, Including Research Assistants \\
\hline $2310 X X$ & Lawyers, and judges, magistrates, and other judicial workers \\
\hline $29112 \mathrm{X}$ & Other Therapists, Including Exercise Physiologists \\
\hline 451011 & First-Line Supervisors of farming, fishing, and forestry workers \\
\hline $472 X X X$ & $\begin{array}{l}\text { Miscellaneous construction workers including solar Photovaltaic Installers, and septic tank servicers and } \\
\text { sewer pipe cleaners }\end{array}$ \\
\hline $49209 X$ & Electrical and electronics repairers, transportation equipment, and industrial and utility \\
\hline $49909 X$ & Other Installation, Maintenance, and Repair Workers \\
\hline $5360 X X$ & Miscellaneous transportation workers including bridge and lock tenders and traffic technicians \\
\hline $5370 X X$ & Conveyor operators and tenders, and hoist and winch operators \\
\hline $537 X X X$ & Miscellaneous Material Moving Workers \\
\hline
\end{tabular}

To calculate import penetration, we begin with data at the US-level (year 2005). We compute sector-specific (4-digit NAICS) import penetration as the ratio between total import of manufactured products of each sector and total 'domestic use' of products of the same sector (import + domestic output - export). Data on import and export by sector are retrieved from Schott (2008), while domestic output is retrieved from the NBER-CES database. We then estimate CZlevel import penetration as the weighted average of sector-specific (4-digit NAICS) national import penetration, using employment by CZ and 4-digit NAICS sector as weights (source: County Business Patterns database).

To account for the presence of shale gas extraction, we obtained geospatial data on shale gas and oil play boundaries from the US Energy Information Administration. ${ }^{20}$ We use GIS to compute a dummy variable equal to 1 if the $\mathrm{CZ}$ overlaps any of the shale oil and gas resources. Thus, the indicator represents the potential for shale oil or gas activity. To avoid endogeneity, we do not include actual drilling activity.

Indicators of wind and photovoltaic energy potential are based on detailed information from the National Renewable Energy Laboratory. ${ }^{21}$ For wind, this information includes speed and

20 https://www.eia.gov/maps/maps.htm, last accessed May 27, 2020.

21 https://www.nrel.gov/gis/index.html, last accessed May 27, 2020. 
variability of winds at different heights and for the presence of obstacles. For solar, this information considers the intensity and slope of solar radiation and for obstacles and terrain slope. We attribute to each $\mathrm{CZ}$ the average indicator of potential for wind and photovoltaic energy generation, ranging from 1 (low potential) to 7 (high potential).

We compute two dummy variables to account for the presence of local stringent environmental regulation to limit air pollution within the Clean Air Act. The dummy variable NA CAA old standard is set to one if at least $1 / 3$ of the $\mathrm{CZ}$ resides in counties that were designed as nonattainment according to National Ambient Air Quality Standards (NAAQS) set in the presample period: carbon oxide (1971), lead (1978), NO2 (1971), ozone (1979; 1997), particulate matter $<10$ micron (1987), particulate matter $<2.5$ micron (1997), SO2 (1971). The dummy variable NA CAA new standards, instead, considers recently approved more stringent NAAQS: lead (2008), ozone (2008), particulate matter <2.5 micron (2006), SO2 (2010).

Finally, we manually detect the presence of Federal R\&D laboratories and state capitals in each $\mathrm{CZ}$ and create two dummy variables.

Table A4 reports descriptive statistics, weighted by population in 2008 , for all our control variables. 
Table A4 - Descriptive statistics of control variables

\begin{tabular}{|c|c|c|c|c|c|}
\hline Variable & mean & s.d. & $\min$ & median & $\max$ \\
\hline Share of empl with GGS $>$ p75 (year 2006) & 0.251 & 0.027 & 0.171 & 0.251 & 0.360 \\
\hline Population 2008 (log) & 14.197 & 1.423 & 10.136 & 14.377 & 16.685 \\
\hline Income per capita $(2005)$ & 38.149 & 8.067 & 18.229 & 37.815 & 77.863 \\
\hline Import penetration (year 2005) & 0.008 & 0.005 & 0.001 & 0.006 & 0.051 \\
\hline Pre trend (2000-2007) employment tot / pop & -0.010 & 0.020 & -0.092 & -0.010 & 0.112 \\
\hline Pre trend (2000-2007) empl manufacturing / pop & -0.015 & 0.010 & -0.090 & -0.015 & 0.031 \\
\hline Pre trend (2000-2007) empl constr / pop & 0.002 & 0.004 & -0.013 & 0.001 & 0.027 \\
\hline Pre trend (2000-2007) empl extractive / pop & 0.001 & 0.003 & -0.009 & 0.000 & 0.101 \\
\hline Pre trend (2000-2007) empl public sect / pop & 0.000 & 0.004 & -0.046 & 0.000 & 0.057 \\
\hline Pre trend (2000-2007) unempl / pop & 0.003 & 0.005 & -0.016 & 0.003 & 0.021 \\
\hline Pre trend (2000-2007) empl edu health / pop & 0.012 & 0.010 & -0.039 & 0.011 & 0.068 \\
\hline Empl manuf (average 2006-2008) / pop & 0.045 & 0.023 & 0.000 & 0.044 & 0.173 \\
\hline Empl constr (average 2006-2008) / pop & 0.023 & 0.007 & 0.001 & 0.022 & 0.088 \\
\hline Empl extractive (average 2006-2008) / pop & 0.002 & 0.006 & 0 & 0.000 & 0.148 \\
\hline Empl public sect (average 2006-2008) / pop & 0.022 & 0.011 & 0.000 & 0.020 & 0.138 \\
\hline Unempl (average 2006-2008) / pop & 0.025 & 0.005 & 0.001 & 0.025 & 0.071 \\
\hline Empl edu health (average 2006-2008) / pop & 0.072 & 0.022 & 0.001 & 0.071 & 0.169 \\
\hline Shale gas extraction in $\mathrm{CZ}$ & 0.343 & 0.475 & 0 & 0 & 1 \\
\hline Potential for wind energy & 1.620 & 0.639 & 1 & 2 & 5 \\
\hline Potential for photovoltaic energy & 5.083 & 0.832 & 4 & 5 & 7 \\
\hline Federal R\&D lab & 0.258 & 0.438 & 0 & 0 & 1 \\
\hline CZ hosts the state capital & 0.222 & 0.415 & 0 & 0 & 1 \\
\hline Nonattainment CAA old standards & 0.694 & 0.461 & 0 & 1 & 1 \\
\hline Nonattainment CAA new standards & 0.365 & 0.481 & 0 & 0 & 1 \\
\hline
\end{tabular}

Notes: data by commuting zone includes only CZ with at least 25000 inhabitants. Statistics weighted by population in 2008.

\section{A3 - Dependent variables: definitions and data sources}

Our main dependent variable is the change in total employment per capita (using population in 2008) compared to the base year 2008. Data on average annual employment level by county is retrieved from the BLS-QCEW (Quarterly Census of Employment and Wages of the Bureau of Labor Statistics). County-level data are then aggregated up at the CZ level. We also use BLS-QCEW to estimate employment by industry (columns 2-5 of Table 5).

Our measure of green employment (column 1 of Table 5) is estimated as:

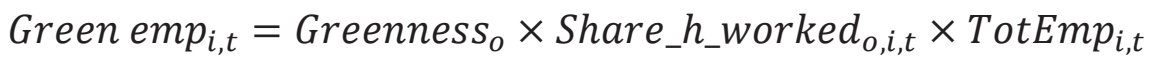

where: 
- Greenness ${ }_{o}$ is computed as the importance-weighted share of green specific tasks over total specific tasks (source: $\mathrm{O}$ NET, version 18.0) in occupation $o$ as in Vona et al. (2019);

- Share_h_worked ${ }_{o, i, t}$ is the share of hours worked by employees in SOC occupation $o$ in $\mathrm{CZ} i$ and year $t$ (source: IPUMS-ACS);

- TotEmp $p_{i, t}$ is total employment in CZ $i$ and year $t$ (source: BLS-QCEW).

Our estimate of green employment is found to be, on average, an upper-bound compared to recent figures due to possible aggregation bias at the occupational level and to the fact that we consider three additional years (2015-2016-2017). Our benchmark is Vona et al. (2019), who estimate green employment using data on 'pure' 6-digit SOC occupational classification (775 occupations) from BLS-OES at the metropolitan and nonmetropolitan area level. According to their estimate, green employment accounts for 3\% of total US employment in 2006-2014. Our estimates here, which use 448 occupations in IPUMS-ACS data by commuting zone, suggest that green employment is $4.6 \%$ of total US employment over a similar but slightly longer timeframe.

An example to illustrate the possible aggregation bias is the following. In ACS the occupation "17-3020 Engineering Technicians, Except Drafters" is not broken down into its 8 6digit occupations. While the average greenness of $17-3020$ is 0.16 , it includes both 6-digit occupations with zero greenness (e.g. "17-3021 Aerospace Engineering and Operations Technicians") and occupations with greenness equal to one (e.g. "17-3025 Environmental Engineering Technicians"). Clearly, taking the unweighted average, as we did here, over-estimate the weight given to green occupations that taking the weighted average, as in Vona et al. (2019) whereby BLS data are available at a more disaggregated level from BLS-OES at the metropolitan and nonmetropolitan area level. The simple reason for this is that the relative size of green 
occupations within a broad category such as "17-3020 Engineering Technicians, Except Drafters" is smaller than the uniform weights that one would attribute in absence of employment statistics at a more disaggregated level. We refer the interested reader to Vona et al. (2019) for further evidence and discussions of the aggregation bias associated with the use of too coarse occupationbased measure of green employment.

Occupational groups (Table 6) are identified following the definition provided by Acemoglu and Autor (2011). The list of SOC occupations (ACS definition) by each macro occupational group is reported in Table A5. Similarly to the measure of greenness, we compute the share of hours worked (weighted by sampling weights) by employees in each macrooccupational group and $\mathrm{CZ}$ over the total hours worked in the $\mathrm{CZ}$ using data from IPUMS-ACS. The number of employees by occupational group is then computed as the product between the share of hours worked in $\mathrm{CZ}$ and the total number of employees (BLS-QCEW).

Table A5 - Macro-occupational groups based on Acemoglu and Autor (2011) (definitions for SOC codes can be found at https://usa.ipums.org/usa-action/variables/OCCSOC\#codes_section)

\begin{tabular}{|l|l|}
\hline $\begin{array}{l}\text { Macro-occupational } \\
\text { group }\end{array}$ & SOC codes \\
\hline $\begin{array}{l}\text { Abstract } \\
\text { occupations }\end{array}$ & $111021,1110 X X, 112011,112020,112031,113011,113021,113031,113040,113051,113061,119013$, \\
& $119021,119030,119041,119051,119071,119081,119111,119121,119141,119151,119199,119 X X X$, \\
& $131011,131021,131022,131023,131041,131051,131070,131081,131111,131121,131 X X X, 132011$, \\
& $132031,132041,132051,132052,132053,132061,132070,132081,132082,132099,151111,151121$, \\
& $151122,151131,151134,15113 X, 151141,151142,151143,151150,151199,152011,152031,1520 X X$, \\
& $171010,171020,172011,172041,172051,172061,172070,172081,1720 X X, 172110,172121,172131$, \\
& $172141,1721 X X, 1721 Y Y, 173010,173020,173031,191010,191020,191030,1910 X X, 192010,192021$, \\
& $192030,192040,192099,193011,193030,193051,1930 X X, 194011,194021,194031,1940 Y Y, 2310 X X$, \\
& $232011,232090,251000,252010,252020,252030,252050,253000,254010,254021,259041,2590 X X$, \\
& $271010,271020,272011,272012,272020,272030,272040,272099,273010,273020,273031,273041$, \\
& $273042,273043,273090,274021,274030,2740 X X, 291011,291020,291031,291041,291051,291060$, \\
& $291071,291081,291122,291123,291124,291125,291126,291127,29112 X, 291131,291181,291199$, \\
& $292010,292021,292030,292041,292050,292061,292071,292081,292090,299000,312010,312020$, \\
& $33909 X, 391010,519080,532010,532020$ \\
\hline Manual occupations & $471011,472011,472031,472040,472050,472061,472071,47207 X, 472080,472111,472121,472130$, \\
& $472140,472150,472161,472181,472211,472 X X X, 473010,474011,474021,474031,474041,474051$, \\
& $474061,475021,475031,475040,4750 X X, 4750 Y Y, 47 X X X X, 491011,492011,492020,492091,492092$, \\
& $492096,492097,492098,49209 X, 493011,493021,493022,493023,493031,493040,493050,493090$, \\
& $499010,499021,499031,499043,499044,49904 X, 499051,499052,499060,499071,499091,499094$, \\
& $499096,499098,49909 X, 511011,512011,512020,512031,512041,512090,513011,513020,513091$, \\
& $513092,513093,514010,514021,514022,514023,514030,514041,514050,5140 X X, 514111,514120$, \\
& $514 X X X, 515111,515112,515113,516011,516021,516031,516040,516050,516063,516064,51606 X$, \\
\hline
\end{tabular}




\begin{tabular}{|l|l|}
\hline & $516093,51609 X, 517011,517021,517041,517042,5170 X X, 518010,518021,518031,518090,519010$, \\
& $519020,519030,519041,519051,519061,519071,519111,519120,519151,519191,519194,519195$, \\
& $519196,519197,519198,5191 X X, 531000,533011,533020,533030,533041,5330 X X, 534010,534031$, \\
& $5340 X X, 535020,5350 X X, 536021,536031,5360 X X, 537021,537030,537051,537061,537062,537063$, \\
& $537064,537070,537081,5370 X X$ \\
\hline Service occupations & $211010,211020,21109 X, 212011,212021,212099,311010,319011,319091,31909 X, 331011,331012$, \\
& $331021,331099,332011,332020,333010,333021,333050,3330 X X, 339011,339021,339030,339091$, \\
& $33909 X, 351011,351012,352010,352021,353011,353021,353022,353031,353041,359021,359031$, \\
& $3590 X X, 371011,371012,372012,37201 X, 372021,373010,391021,392021,393010,393021,393031$, \\
& $393090,394000,395011,395012,395090,396010,396030,397010,399011,399021,399030,399041$, \\
\hline Clerical occupations & $399099,536051,537 X X X$ \\
\hline & $113071,131030,132021,254031,411011,411012,412010,412021,412022,412031,413011,413021$, \\
& $413031,413041,413099,414010,419010,419020,419031,419041,419091,419099,431011,432011$, \\
& $432021,432099,433011,433021,433031,433041,433051,433061,433071,434011,434031,434041$, \\
& $434051,434061,434071,434081,434111,434121,434131,434141,434161,434171,434181,434199$, \\
& $434 X X X, 435011,435021,435030,435041,435051,435052,435053,435061,435071,435081,435111$, \\
& $436010,439011,439021,439022,439041,439051,439061,439071,439081,439111,439 X X X$ \\
\hline
\end{tabular}

In our focus on manual occupations (Table 7), we identify sub-categories of manual workers based on data from IPUMS-ACS. We compute the hourly wage (column 1) as the ratio between total wages received and total annual hours worked. In column 2 and 3 we use, respectively, the share of manual workers with hourly wage above or below US-median hourly wage in the US. Finally, in columns 4 and 5 we consider the educational attainment of manual workers using information on educational attainment from IPUMS-ACS: we define manual workers with high school degree or more as those manual workers that completed at least the 12th grade.

Table A6 - Descriptive statistics of dependent variables

\begin{tabular}{|c|c|c|c|c|c|}
\hline Variable & mean & s.d. & $\min$ & median & $\max$ \\
\hline Total employment / pop & 0.429 & 0.066 & 0.014 & 0.435 & 0.956 \\
\hline Employment in abstract occ / pop & 0.156 & 0.042 & 0.004 & 0.155 & 0.327 \\
\hline Employment in manual occ / pop & 0.095 & 0.022 & 0.003 & 0.093 & 0.348 \\
\hline Employment in service occ / pop & 0.073 & 0.012 & 0.002 & 0.073 & 0.154 \\
\hline Employment in clerical occ / pop & 0.102 & 0.018 & 0.003 & 0.104 & 0.173 \\
\hline Green employment / pop & 0.020 & 0.005 & 0.001 & 0.020 & 0.056 \\
\hline Employment in manufacturing / pop & 0.041 & 0.022 & 0.000 & 0.038 & 0.180 \\
\hline Employment in construction / pop & 0.020 & 0.007 & 0.000 & 0.019 & 0.098 \\
\hline Employment in profess. scient. tech. services / pop & 0.024 & 0.013 & 0.000 & 0.024 & 0.074 \\
\hline Employment in waste management / pop & 0.025 & 0.009 & 0.000 & 0.025 & 0.108 \\
\hline Average h. wage of manual workers & 18.606 & 3.078 & 10.167 & 18.395 & 102.902 \\
\hline Manual workers with h wage $>$ US-median for manual / pop & 0.053 & 0.013 & 0.001 & 0.052 & 0.238 \\
\hline Manual workers with $\mathrm{h}$ wage $<$ US-median for manual $/$ pop & 0.042 & 0.013 & 0.001 & 0.041 & 0.123 \\
\hline Manual workers with $>$ high school degree / pop & 0.028 & 0.007 & 0.001 & 0.027 & 0.135 \\
\hline Manual workers with high school degree or less / pop & 0.067 & 0.017 & 0.002 & 0.065 & 0.213 \\
\hline
\end{tabular}

Notes: data by commuting zone includes only CZ with at least 25000 inhabitants. Statistics weighted by population in 2008. 


\section{A4 - Limits of using non-ARRA local spending from USASPENDING.GOV}

Pre-ARRA government spending on the green economy are the most serious candidate to explain pre-trends in green ARRA. Quality data on green spending before ARRA would enable us to clearly disentangle the effect of ARRA from that of past government spending. Data on local government spending are publicly available at USASPENDING.GOV. However, for two reasons these data are not good proxies of local green spending before ARRA. First, while EPA spending could be considered as 'green' both during ARRA and prior of ARRA, the same is not true for DoE. While a very large part of DoE local spending in ARRA goes to fund renewable energy investments, energy efficiency and other green programmes (Aldy, 2013), much DoE spending in earlier years was aimed at the exploitation and use of fossil fuels and nuclear energy (Department of Energy Budget Highlights, various years). More importantly, local spending for assistance available at USASPENDING.gov (e.g. CFDA Catalogue of Federal Domestic Assistance) is attributed to the prime recipient while sub-awards are consistently recorded only starting from 2010-2012 onwards. As a result, assistance given to local state governments to be distributed to countries is recorded as fully attributed to the $\mathrm{CZ}$ where the state capital is. Despite these important limitations, we do observe a relatively strong correlation (0.485) between DoE+EPA local spending per capita in 2005-2007 and DoE+EPA (i.e. green) ARRA spending per capita. Overall, we can use these data to build our instrument but not as a direct proxy of pre-ARRA spending. 


\section{Appendix B - Quantification of the green ARRA effects}

Because we use a log-log model with per capita variables, interpreting the magnitude of our coefficients is challenging. However, converting our elasticities to jobs created per million dollars of ARRA spending produces estimates that are comparable to other papers.

For this conversion, define the predicted value from our model as:

$$
\begin{aligned}
\hat{y}_{i, t}=\log \left(\frac{Y_{i, t}}{\text { pop }_{i, 2008}}\right)-\log \left(\frac{Y_{i, 2008}}{\text { pop }_{i, 2008}}\right) \\
=\hat{\beta}_{0}+\sum_{k} \widehat{\gamma_{k}} \log \left(\frac{\text { GreenARRA }}{\text { pop }_{i, 2008}}\right)+\sum_{k} \widehat{\alpha_{k}} \log \left(\frac{\text { NonGreenARRA }_{i}}{\text { pop }_{i, 2008}}\right)+\boldsymbol{X}^{\prime} \widehat{\boldsymbol{\beta}}
\end{aligned}
$$

We can add \$1 million of green or non-green ARRA and re-calculate:

$$
\begin{aligned}
\hat{y}_{i, t}^{+1}=\log \left(\frac{Y_{i, t}^{+1}}{\text { pop }_{i, 2008}}\right)-\log \left(\frac{Y_{i, 2008}}{\text { pop }_{i, 2008}}\right) \\
=\hat{\beta}_{0}+\sum_{k} \widehat{\gamma_{k}} \log \left(\frac{\text { GreenARRA }_{i}+1}{\text { pop }_{i, 2008}}\right)+\sum_{k} \widehat{\alpha_{k}} \log \left(\frac{\text { NonGreenARRA }_{i}}{\text { pop }_{i, 2008}}\right) \\
+\boldsymbol{X}^{\prime} \widehat{\boldsymbol{\beta}}(2)
\end{aligned}
$$

Subtracting one from the other gives us:

$$
\begin{aligned}
\hat{y}_{i, t}^{+1}-\hat{y}_{i, t}= & \log \left(\frac{Y_{i, t}^{+1}}{\text { pop }_{i, 2008}}\right)-\log \left(\frac{Y_{i, 2008}}{\text { pop }_{i, 2008}}\right)-\log \left(\frac{Y_{i, t}}{\text { pop }_{i, 2008}}\right)+\log \left(\frac{Y_{i, 2008}}{\text { pop }_{i, 2008}}\right) \\
= & \log \left(\frac{Y_{i, t}^{+1}}{\text { pop }_{i, 2008}}\right)-\log \left(\frac{Y_{i, t}}{\text { pop }_{i, 2008}}\right) \\
& =\sum_{k} \widehat{\gamma_{k}} \log \left(\frac{\text { GreenARR }_{i}+1}{\text { pop }_{i, 2008}}\right)-\sum_{k} \widehat{\gamma_{k}} \log \left(\frac{\text { GreenARR }_{i}}{\text { pop }_{i, 2008}}\right)
\end{aligned}
$$

We can re-write the log quotients to simplify further: 


$$
\begin{aligned}
\hat{y}_{i, t}^{+1}-\hat{y}_{i, t}= & \log \left(\frac{Y_{i, t}^{+1}}{\operatorname{pop}_{i, 2008}}\right)-\log \left(\frac{Y_{i, t}}{\operatorname{pop}_{i, 2008}}\right) \\
= & \log \left(Y_{i, t}^{+1}\right)-\log \left(\operatorname{pop}_{i, 2008}\right)-\log \left(Y_{i, t}\right)+\log \left(p o p_{i, 2008}\right) \\
= & \log \left(Y_{i, t}^{+1}\right)-\log \left(Y_{i, t}\right)=\log \left(\frac{Y_{i, t}^{+1}}{Y_{i, t}}\right)(4)
\end{aligned}
$$

Converting to levels, we get:

$$
\exp ^{\log \left(\frac{Y_{i, t}^{+1}}{Y_{i, t}}\right)}=\left(\frac{Y_{i, t}^{+1}}{Y_{i, t}}\right)
$$

We want

$$
Y_{i, t}^{+1}-Y_{i, t}=\left(\frac{Y_{i, t}^{+1}}{Y_{i, t}}\right) Y_{i, t}-Y_{i, t}=Y_{i, t}\left\{\exp ^{\log \left(\frac{Y_{i, t}^{+1}}{Y_{i, t}}\right)}-1\right\}
$$

Using (3), (4) and (5) we can replace $\left(\mathrm{Y}^{+1} / \mathrm{Y}\right)$ above with the difference of our predicted values from (3), giving us:

$$
Y_{i, t}^{+1}-Y_{i, t}=Y_{i, t}\left\{\exp ^{\sum_{k} \widehat{\gamma_{k}} \log \left(\frac{\text { GreenARR }_{i}+1}{\text { pop }_{i, 2008}}\right)-\sum_{k} \widehat{\gamma_{k}} \log \left(\frac{\text { GreenARRA }_{i}}{\text { pop }_{i, 2008}}\right)}-1\right\}
$$

For a given time period (e.g. short-run or long-run), this simplifies to:

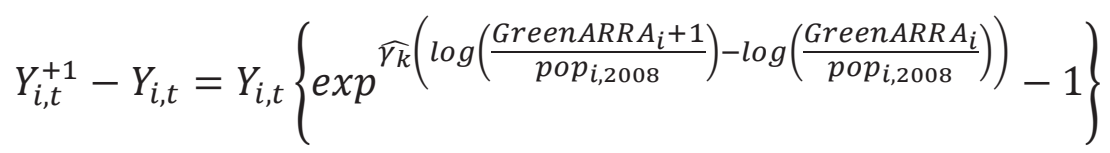




\section{Appendix C - First stage IV and overidentification test}

Table C1 - First stage IV (exactly identified)

\begin{tabular}{lcc}
\hline Dep var: Green (EPA+DoE) ARRA per capita (in log) & $(1)$ & $(2)$ \\
\hline Shift-share IV for green ARRA & $0.0963^{* * *}$ & $0.103^{* * *}$ \\
& $(0.0270)$ & $(0.0270)$ \\
\hline US-Division dummies & Yes & No \\
State dummies & No & Yes \\
Vigintiles of non-green ARRA per capita & Yes & Yes \\
\hline R squared & 0.407 & 0.453 \\
F-test of excluded IV from first stage & 12.72 & 13.80 \\
N & 587 & 587 \\
\hline
\end{tabular}

Notes: OLS model weighted by CZ population in 2008. Sample: CZ with at least 25,000 residents in 2008. Standard errors clustered by state in parentheses. $* \mathrm{p}<0.1, * * \mathrm{p}<0.05, * * * \mathrm{p}<0.01$. Control variables: Share of empl with GGS $>$ p 75 (year 2006), Population 2008 (log), Income per capita (2005), Import penetration (year 2005), Pre trend (2000-2007) empl manufacturing / pop, Pre trend (2000-2007) employment tot / pop, Pre trend (2000-2007) empl constr / pop, Pre trend (2000-2007) empl extractive / pop, Pre trend (2000-2007) empl public sect / pop, Pre trend (20002007) unempl / pop, Pre trend (2000-2007) empl edu health / pop, Empl manuf (average 20062008) / pop, Empl constr (average 2006-2008) / pop, Empl extractive (average 2006-2008) / pop, Empl public sect (average 2006-2008) / pop, Unempl (average 2006-2008) / pop, Empl edu health (average 2006-2008) / pop, Shale gas extraction in CZ interacted with year dummies, Potential for wind energy interacted with year dummies, Potential for photovoltaic energy interacted with year dummies, Federal R\&D lab, CZ hosts the state capital, Nonattainment CAA old standards, Nonattainment CAA new standards.

Table C2 - First stage IV (overidentified)

\begin{tabular}{lcc}
\hline Dep var: Green (EPA+DoE) ARRA per capita (in log) & $(1)$ & $(2)$ \\
\hline Shift-share IV for green ARRA: EPA spending & 0.0359 & 0.0214 \\
& $(0.0245)$ & $(0.0305)$ \\
Shift-share IV for green ARRA: DOE spending & $0.0503^{* * *}$ & $0.0560^{* * *}$ \\
& $(0.0151)$ & $(0.0149)$ \\
\hline US-Division dummies & Yes & No \\
State dummies & No & Yes \\
Vigintiles of non-green ARRA per capita & Yes & Yes \\
\hline R squared & 0.407 & 0.453 \\
F-test of excluded IV from first stage & 5.89 & 8.24 \\
N & 587 & 587 \\
\hline
\end{tabular}

Notes OLS model weighted by CZ population in 2008. Sample: $\mathrm{CZ}$ with at least 25,000 residents in 2008. Standard errors clustered by state in parentheses. ${ }^{*} \mathrm{p}<0.1, * * \mathrm{p}<0.05, * * * \mathrm{p}<0.01$. Control variables: Share of empl with GGS>p75 (year 2006), Population 2008 (log), Income per capita (2005), Import penetration (year 2005), Pre trend (2000-2007) empl manufacturing / pop, Pre trend (2000-2007) employment tot / pop, Pre trend (2000-2007) empl constr / pop, Pre trend (2000-2007) empl extractive / pop, Pre trend (2000-2007) empl public sect / pop, Pre trend (20002007) unempl / pop, Pre trend (2000-2007) empl edu health / pop, Empl manuf (average 20062008) / pop, Empl constr (average 2006-2008) / pop, Empl extractive (average 2006-2008) / pop, Empl public sect (average 2006-2008) / pop, Unempl (average 2006-2008) / pop, Empl edu health (average 2006-2008) / pop, Shale gas extraction in CZ interacted with year dummies, Potential for wind energy interacted with year dummies, Potential for photovoltaic energy interacted with year dummies, Federal R\&D lab, CZ hosts the state capital, Nonattainment CAA old standards, Nonattainment CAA new standards. 
Table C3 - IV estimates (overidentified model)

\begin{tabular}{|c|c|c|}
\hline Dep var: Change in log employment per capita compared to 2008 & $(1)$ & $(2)$ \\
\hline Green ARRA per capita (log) x D2005_2007 & $\begin{array}{c}0.00835 \\
(0.00600)\end{array}$ & $\begin{array}{c}0.00715 \\
(0.00470)\end{array}$ \\
\hline Green ARRA per capita (log) x D2009_2012 & $\begin{array}{c}0.00551 \\
(0.00469)\end{array}$ & $\begin{array}{l}0.00798 * * \\
(0.00392)\end{array}$ \\
\hline Green ARRA per capita $(\log ) \times$ D2013_2017 & $\begin{array}{c}0.0171 \\
(0.0108)\end{array}$ & $\begin{array}{l}0.0191 * * \\
(0.00815)\end{array}$ \\
\hline $\begin{array}{l}\text { US-Division dummies x period dummies } \\
\text { State dummies x period dummies }\end{array}$ & $\begin{array}{l}\text { Yes } \\
\text { No }\end{array}$ & $\begin{array}{l}\text { No } \\
\text { Yes }\end{array}$ \\
\hline \multicolumn{3}{|l|}{ Comparison across periods: } \\
\hline Green ARRA per capita (log): 2009-2012 vs 2005-2007 & $\begin{array}{l}-0.00285 \\
(0.00510)\end{array}$ & $\begin{array}{l}0.000825 \\
(0.00446)\end{array}$ \\
\hline Green ARRA per capita (log): 2013-2017 vs 2005-2007 & $\begin{array}{c}0.00870 \\
(0.00934)\end{array}$ & $\begin{array}{c}0.0119 \\
(0.00753)\end{array}$ \\
\hline $\begin{array}{l}\mathrm{N} \text { of jobs created by } \$ 1 \mathrm{mln} \text { green ARRA: short term (2009-2012) } \\
\text { s.e. }\end{array}$ & $\begin{array}{l}-12.35 \\
(22.10)\end{array}$ & $\begin{array}{c}3.58 \\
(19.35)\end{array}$ \\
\hline $\begin{array}{l}\mathrm{N} \text { of jobs created by } \$ 1 \mathrm{mln} \text { green ARRA: long term (2013-2017) } \\
\text { s.e. }\end{array}$ & $\begin{array}{c}40.42 \\
(43.39)\end{array}$ & $\begin{array}{c}55.28 \\
(34.98)\end{array}$ \\
\hline Sargan Chi sq test of overidentifying restrictions ( $p$-value) & 0.510 & 0.0033 \\
\hline $\mathrm{N}$ of $\mathrm{CZ}$ & 587 & 587 \\
\hline Observations & 7631 & 7631 \\
\hline \multicolumn{3}{|c|}{$\begin{array}{l}\text { Notes: instrumental variable regressions weighted by CZ population in 2008. Sample: CZ with at least } 25,000 \\
\text { residents in 2008. Standard errors clustered by state in parentheses. } * \text { p }<0.1, * * \text { p }<0.05, * * * \text { p }<0.01 \text {. Year } \\
\text { dummies included. Additional control variables (interacted with D2002_2007, D2009_2012 and } \\
\text { D2013_2017 dummies): Vigintiles of non-green ARRA per capita, Population } 2008 \text { (log), Income per capita } \\
\text { (2005), Import penetration (year 2005), Share of empl with GGS }>\text { p75 (year 2006), Pre trend (2000-2007) } \\
\text { empl manufacturing / pop, Pre trend (2000-2007) employment tot / pop, Pre trend (2000-2007) empl constr / } \\
\text { pop, Pre trend (2000-2007) empl extractive / pop, Pre trend (2000-2007) empl public sect / pop, Pre trend } \\
\text { (2000-2007) unempl / pop, Pre trend (2000-2007) empl edu health / pop, Empl manuf (average 2006-2008)/ } \\
\text { pop, Empl constr (average 2006-2008) / pop, Empl extractive (average 2006-2008) / pop, Empl public sect } \\
\text { (average 2006-2008) / pop, Unempl (average 2006-2008) / pop, Empl edu health (average 2006-2008) / pop, } \\
\text { Shale gas extraction in CZ interacted with year dummies, Potential for wind energy interacted with year } \\
\text { dummies, Potential for photovoltaic energy interacted with year dummies, Federal R\&D lab, CZ hosts the } \\
\text { state capital, Nonattainment CAA old standards, Nonattainment CAA new standards. Endogenous variable } \\
\text { (columns } 3 \text { and 4): Green ARRA per capita (log). Excluded IV from the first stage: shift-share IV of ARRA } \\
\text { spending by Department/Agency (EPA and DOE separately); local spending share 2001-2004 }\end{array}$} \\
\hline
\end{tabular}




\section{Appendix References}

Acemoglu, D. and Autor, D. 2011. Skills, Tasks and Technologies: Implications for Employment and Earnings. Handbook of Labor Economics Volume 4, Orley Ashenfelter and David E. Card (eds.), Amsterdam: Elsevier.

Aldy, J.E. 2013. Policy Monitor-A preliminary assessment of the American Recovery and Reinvestment Act's Clean Energy Package. Review of Environmental Economics and Policy, 7(1): 136-155.

Department of Energy. FY 20XX Congressional Budget Request. Budget Highlights. Office of Management, Budget, and Evaluation, various years.

Ruggles, S., Flood, S., Goeken, R., Grover, J., Meyer, E., Pacas, J. and Sobek, M., 2020. IPUMS USA: Version 10.0 [dataset]. Minneapolis, MN: IPUMS. https://doi.org/10.18128/D010.V10.0

Schott, P. K., 2008. The relative sophistication of Chinese exports. Economic Policy, 23, 5-49.

Vona, F., Marin, G., Consoli, D., Popp, D., 2018. Environmental Regulation and Green Skills: an empirical exploration, Journal of the Association of Environmental and Resource Economists vol. 5(4): 713-753

Vona, F., Marin, G., Consoli, D., 2019. Measures, Drivers and Effects of Green Employment: evidence from US metropolitan and non-metropolitan areas, 2006-2014, Journal of Economic Geography 19, 1021-1048. 